\title{
Finite element analysis of crustal deformation in the Ou Backbone Range, northeastern Japan, with non-linear visco-elasticity and plasticity: effects of non-uniform thermal structure
}

\author{
Bunichiro Shibazaki ${ }^{1}$, Kazuteru Garatani $^{2}$, and Hiroshi Okuda ${ }^{3}$ \\ ${ }^{1}$ International Institute for Seismology and Earthquake engineering, Building Research Institute, 1 Tatehara, Tsukuba, Ibaraki 305-0082, Japan \\ ${ }^{2}$ ITOCHU Techno-Solutions Corporation, 3-2-5 Kasumigaseki, Chiyoda-ku, Tokyo 100-6080, Japan \\ ${ }^{3}$ Research into Artifacts, Center for Engineering, The University of Tokyo, 5-1-5 Kashiwanoha, Kashiwa, Chiba 277-8568, Japan
}

(Received February 13, 2006; Revised December 4, 2006; Accepted January 15, 2007; Online published June 27, 2007)

\begin{abstract}
A finite element analysis with non-linear visco-elasticity and plasticity was carried out with the aim of constructing a model of the slip and deformation processes in the deeper parts of the seismogenic zones of inland earthquakes. Our finite element code is based on the GeoFEM parallel finite element code and was developed using plug-ins to adopt several non-linear functions. We consider the effects of geothermal structures in the crust in a compressional tectonic setting to model the deformation and faulting that occur around the Ou Backbone Range in northeastern Japan. We set an area of high geothermal gradient in the center of the model. The numerical results show that shortening deformation due to non-linear viscous flow occurs in the high-temperature area in the lower part of the crust, which results in shear faulting in the upper part of the crust. In the case where the crust comprises two layers - the upper crust (quartz diorite) and the lower crust (wet diabase) —a weak viscous zone appears in the lower part of the upper crust and a strong viscous or plastic zone appears at the upper part of the lower crust. Our numerical results are able to explain the deformation and faulting that occur around the $\mathrm{Ou}$ Backbone Range in northeastern Japan.
\end{abstract}

Key words: GeoFEM, crustal deformation, non-linear visco-elasticity, plasticity, thermal structure, Ou Backbone Range.

\section{Introduction}

In the case of interplate earthquakes, stress is believed to accumulate as a result of a fault slip being held back relative to the plate motion. There are many numerical models of interplate earthquakes that take this kind of stress loading processes into consideration (see Tse and Rice, 1986). Matsu'ura and Sato (1997) recently developed a comprehensive model for the loading processes of interplate earthquakes, but the tectonic loading and generation processes of large intraplate earthquakes have remained unresolved problems.

Iio and Kobayashi (2002) reviewed several models for the generation processes of large intraplate earthquakes, two of which are end member models. In one of these, where stress is uniformly loaded over a broad region and low-strength pre-existing faults exist in the upper crust, intraplate earthquakes are generated on the pre-existing faults, and faulting in the upper crust controls the lower crustal flow. Johnston and Kanter (1990) found that intraplate earthquakes in stable continental crust are commonly associated with the pre-existing weak zones which are ancient rift zones. In the second end member model, in which a local weak zone exists in the lower crust and deformation concentrates on this zone, the localized deformation results in the concen-

Copyright (c) The Society of Geomagnetism and Earth, Planetary and Space Sciences (SGEPSS); The Seismological Society of Japan; The Volcanological Society of Japan; The Geodetic Society of Japan; The Japanese Society for Planetary Sciences; TERRAPUB. tration of stress and the generation of earthquakes in the upper crust (see Iio and Kobayashi, 2002; Kenner and Segall, 2000). Iio et al. (2004) developed a model of the deformation process around the Nagamachi-Rifu fault zone in northeastern Japan, in order to clarify the stress accumulation process on an inland earthquake fault. They found that the observed surface deformation can be explained by models having a weak zone in the lower crust. In their simulation, linear visco-elasticity for the crustal deformation is considered, but nonlinear viscous flow is not considered.

In Japan, many large inland earthquakes occur along the strain concentration zone (Sagiya et al., 2000; Miura et al., 2004). Based on GPS observations, Sagiya et al. (2000) reported the presence of a strain concentration zonecalled the Niigata-Kobe Tectonic Zone-in central Japan, the cause of which has since been investigated by several authors (Iio et al., 2002; Hyodo and Hirahara, 2003; Yamasaki and Seno, 2005). Also using GPS data, Miura et al. (2004) determined the presence of another strain concentration zone along the $\mathrm{Ou}$ Backbone Range in northeastern Japan. Both of these strain concentration zones are thought to be related to the weak zones in the crust and upper mantle structures.

Hasegawa et al. (2005) proposed a model explaining the crustal deformation process and shallow seismic activity beneath northeastern Japan based on high-resolution seismological observation. In their model, aqueous fluids are transported upward through a hot upwelling flow caused by the 
subduction-induced convection to reach shallow levels beneath the Ou Backbone Range in northeastern Japan. These aqueous fluids are thought to weaken the crustal rock both chemically and mechanically (see Kohlstedt et al., 1995). The heat flow along the Ou Backbone Range was also found to be high (Tanaka and Ishikawa, 2002). Hasegawa et al. (2005) propose that a shortening deformation occurs in the weak region in the lower crust beneath the Ou Backbone Range and that this deformation causes shear faulting in the upper crust. It is believed that faulting processes in the northeastern Japan are controlled by non-linear viscous flow in the weak zone in the lower crust. The model of crustal deformation proposed by Hasegawa et al. (2005) has not been verified by a numerical simulation.

The aim of the study reported here was to investigate the earthquake generation processes in northeastern Japan and, more specifically, to verify the deformation model proposed by Hasegawa et al. (2005) by a numerical simulation. To investigate the hypotheses of the generation processes of large inland earthquakes, we need to consider non-linear viscous flow and shear localization in the lower crust and faulting in the upper crust using a method such as a finite element method (FEM). In the lower crust, because of high temperature, non-Newtonian power-law flow due to dislocation creep is thought to predominate. To construct a realistic model of the slip and deformation processes at the deeper part of the seismogenic zone, both faulting in the upper crust and nonlinear visco-elasticity in the lower crust need to be taken into account. The faulting process can be represented by plastic deformation determined by the MohrCoulomb criterion and the associated flow rule. We must also use a large deformation analysis since the deformations are large in our problems. Here, the deformations of a continuum comprise two distinct parts: rigid motions and all changes of body shape resulting in straining.

Many studies have been published on crustal deformation considering plastic deformation in the upper crust and viscous flow in the lower crust. Ellis et al. (2001) investigated shear localization and faulting in the crust. Taking both non-Newtonian power creep and plasticity with the Mohr-Coulomb criterion into consideration, they investigated the lower crustal localization induced by a shearzone in the mantle lithosphere. More recently, Ellis and Stöckhert (2004) found that termination of a fault rupture at the lower end of the seismogenic zone can promote shear localization in the mid and lower crust. Regenauer-Lieb et al. (2001) investigated shear localization processes into which they accounted for the effects of water and viscous dissipation. Other authors have studied the generation of faulting and viscous flow during lithospheric extension while considering both non-Newtonian power creep and plasticity (e.g. Lavier and Buck, 2002; Huismans et al., 2005).

In the present study we used GeoFEM, a parallel finite element analysis system, developed at the Research Institute for Information Science and Technology (RIST) (Garatani et al., 2001a). GeoFEM incorporates a function of linear visco-elastic analysis. For example, using this code, Hyodo and Hirahara (2003) simulated strain concentration in the Niigata-Kobe Tectonic Zone of central Japan. However,
GeoFEM did not incorporate several functions for nonlinear visco-elasticity, plasticity with the Mohr-Coulomb criterion, and large deformation. For this reason, we have extended GeoFEM to include these non-linear functions, as previously presented by Garatani et al. (2003).

In this paper, we first present the formulations of the extended non-linear functions. We then attempt to model the deformation and faulting processes that occur around the Ou Backbone Range in northeastern Japan, focusing on the case where a high thermal gradient region exists in the crust in a compressional tectonic setting and examining how non-linear viscous flow in the lower part of the crust causes shear faulting in the upper part of the crust.

\section{Method of Analysis}

In the field of solid mechanics, non-linearity can be classified into three categories (Zienkiewicz and Taylor, 1994; Bathe, 1996). (1) If the constitutive relations between stress and strain are nonlinear, the problem can be categorized as a nonlinear material problem. In our code, nonlinear visco-elasticity and plasticity functions are implemented. If the deformation is small, an approximately linear relationship is formed between strain and displacement: this is termed an infinitesimal deformation problem. (2) If the deformation is large, non-linearity should be assumed between strain and displacement, and the problem can be categorized as geometrical non-linearity or a large deformation problem. Our code includes an approximate analysis for large deformation. (3) The third category is nonlinearity of the boundary conditions, such as frictional constitutive relationships. In our code, the fault is modeled as a plastic zone in a continuum model, and the Mohr-Coulomb criterion is used to represent the frictional behavior. However, a frictional constitutive relationship that generates earthquake instability has not been included. A parallel finite element code, GeoFEM, was extended to deal with nonlinear visco-elasticity and plasticity functions, and the approximate analysis for large deformation by using plugin features (Garatani et al., 2003).

\subsection{The GeoFEM platform}

GeoFEM is a parallel finite element analysis system intended for various solid-earth applications to solve multiphysics/multi-scale problems. The system includes parallel pre- and post-processing functions for finite element analysis subsystems. In addition, GeoFEM has a platform feature from which various solid earth models might be read in plug-in style (Garatani et al., 2001a). The non-linear analysis functions developed in this investigation were constructed onto the GeoFEM platform as new function modules in the structural subsystem (Garatani et al., 2003). The benefits of using the GeoFEM system are lower development costs and common model data. Furthermore, the system is equipped for highly effective parallel computing. These features are advantageous in large-scale simulations.

\subsection{Approximate analysis for large deformation}

The total Lagrange (T. L.) and updated Lagrange (U. L.) methods (Bathe, 1996) can be used to solve large deformation problems. The fundamental differences between the two methods arise from their reference coordinate systems: the former refers to the initial undeformed configuration, 
while the latter refers to the updated deformed configuration after loading is applied. We selected the U. L. method because it generally has a wider range of applications. The Jaumann and nominal stresses are generally used in the U. L. method; however, these stresses are approximated by the Cauchy stress defined at the updated coordinate because of the relatively small rigid rotation and small strain for each time increment. The details of the formulation used in our code are given in Appendix A. This type of the approximate analysis for a large deformation was adopted in the recent version of TEKTON (Melosh and Raefsky, 1980).

\subsection{Constitutive laws}

In this analysis we consider elasticity, non-linear power law creep, and plasticity with the Mohr-Coulomb criterion. Material behaves according to non-linear visco-elasticity if the yielding function $f(\boldsymbol{\sigma})<0$; however, it behaves as plasticity if plastic yielding occurs $(f(\boldsymbol{\sigma})=0)$. If the yielding function $f(\boldsymbol{\sigma})<0$, the total strain rate $\dot{\boldsymbol{\varepsilon}}$ can be expressed by the sum of elastic strain rate $\dot{\boldsymbol{\varepsilon}}^{e}$ and strain rate $\dot{\boldsymbol{\varepsilon}}^{c}$ caused by power law creep:

$$
\dot{\boldsymbol{\varepsilon}}=\dot{\boldsymbol{\varepsilon}}^{e}+\dot{\boldsymbol{\varepsilon}}^{c}
$$

Elastic strain rate $\dot{\boldsymbol{\varepsilon}}^{e}$ can be written using the matrix of elastic constants $\mathbf{D}^{e}$ :

$$
\dot{\boldsymbol{\varepsilon}}^{e}=\mathbf{D}^{e^{-1}} \dot{\boldsymbol{\sigma}}
$$

The non-linear viscous flow rule, installed in the developed code, can be expressed by the following form in which the strain rate $\dot{\boldsymbol{\varepsilon}}^{c}$ caused by power law creep is a function of stresses defined as $\boldsymbol{\beta}\left(\boldsymbol{\sigma}^{\prime}\right)$ :

$$
\begin{aligned}
\dot{\boldsymbol{\varepsilon}}^{c} & =\frac{1}{\eta}\left(\frac{\bar{\sigma}}{\eta}\right)^{n-1} \boldsymbol{\sigma}^{\prime} \equiv \boldsymbol{\beta}\left(\boldsymbol{\sigma}^{\prime}\right), \\
\bar{\sigma} & =\sqrt{\frac{3}{2} J_{2}} \\
J_{2} & =\sigma_{1}^{\prime} \sigma_{2}^{\prime}+\sigma_{2}^{\prime} \sigma_{3}^{\prime}+\sigma_{3}^{\prime} \sigma_{1}^{\prime},
\end{aligned}
$$

where $\boldsymbol{\sigma}^{\prime}$ is the deviatoric stress tensor, $\bar{\sigma}$ is the equivalent deviatoric stress, and $J_{2}$ is the second invariant of the deviatoric stress tensor, which are defined using the principal deviatoric stress components $\sigma_{1}^{\prime}, \sigma_{2}^{\prime}$, and $\sigma_{3}^{\prime}$. Here, the temperature dependence of coefficient $\eta$ is expressed as:

$$
\eta=B \exp (Q / n R T)
$$

where $R$ is the gas constant, $T$ is absolute temperature, $Q$ is the activation energy, $n$ is the power-low exponent, and $B$ is a constant.

The plastic yielding can occur when the stress state reaches the yield surface: $f(\boldsymbol{\sigma})=0$. The total strain rate can, therefore, be expressed as the sum of elastic strain rate $\dot{\boldsymbol{\varepsilon}}^{e}$ and plastic strain rate $\dot{\boldsymbol{\varepsilon}}^{p}$ with the Mohr-Coulomb criterion:

$$
\dot{\boldsymbol{\varepsilon}}=\dot{\boldsymbol{\varepsilon}}^{e}+\dot{\boldsymbol{\varepsilon}}^{p}
$$

In this study, the Mohr-Coulomb criterion was adopted to model frictional faulting. We use the finite element method for plasticity that is presented in Owen and Hinton (1980).
The Mohr-Coulomb criterion can be expressed as:

$$
\begin{aligned}
f= & -I_{1} \sin \phi+\left(\sqrt{J_{2}} / 2\right)\{\sqrt{3}(3-\sin \phi) \cos \theta \\
& +3(1+\sin \phi) \sin \theta\}-3 c \cos \phi=0, \\
\cos 3 \theta= & \frac{3 \sqrt{3}}{2} \frac{J_{3}}{\left(J_{2}\right)^{3 / 2}}, \\
I_{1}= & \sigma_{1}+\sigma_{2}+\sigma_{3}, \\
J_{3}= & \sigma_{1}^{\prime} \sigma_{2}^{\prime} \sigma_{3}^{\prime},
\end{aligned}
$$

where $I_{1}$ is the first invariant of the stress tensor, $J_{3}$ denotes the third invariant of the deviatoric stress tensor, $\phi$ is the angle of internal friction, and $c$ is the cohesion. To determine the plastic flow after yielding, we use the associated flow rule in which $\dot{\boldsymbol{\varepsilon}}^{p}$ is normal to the yield surface $f(\boldsymbol{\sigma})=0$ :

$$
d \boldsymbol{\varepsilon}^{p}=\lambda \frac{\partial f}{\partial \boldsymbol{\sigma}},
$$

where $\lambda$ is a proportionality constant.

Here we consider a general case where $\phi$ and $c$ are functions of $\boldsymbol{\varepsilon}^{p}$. In this case, $f$ is also a function of $\boldsymbol{\varepsilon}^{p}$ : $f\left(\boldsymbol{\sigma}, \boldsymbol{\varepsilon}^{p}\right)$. When plastic yielding is occurring, the stresses are on the yield surface. Therefore,

$$
d f=\left(\frac{\partial f}{\partial \boldsymbol{\sigma}}\right)^{T} d \boldsymbol{\sigma}+\left(\frac{\partial f}{\partial \boldsymbol{\varepsilon}^{p}}\right)^{T} d \boldsymbol{\varepsilon}^{p}=0,
$$

where ${ }^{T}$ indicates the operation of transposition. From Eqs. (2), (5), (7), and (8), we obtain the following incremental elasto-plastic constitutive relationship (see Appendix C):

$$
d \boldsymbol{\sigma}=\mathbf{D}^{e p} d \boldsymbol{\varepsilon},
$$

where $\mathbf{D}^{e p}$ denotes the following elasto-plastic matrix:

$$
\begin{aligned}
\mathbf{D}^{e p} & =\mathbf{D}^{e}+\mathbf{D}^{p} \\
\mathbf{D}^{p} & =-\frac{\mathbf{D}^{e} \frac{\partial f}{\partial \boldsymbol{\sigma}}\left(\frac{\partial f}{\partial \boldsymbol{\sigma}}\right)^{T} \mathbf{D}^{e}}{-\left(\frac{\partial f}{\partial \boldsymbol{\varepsilon}^{p}}\right)^{T} \frac{\partial f}{\partial \boldsymbol{\sigma}}+\left(\frac{\partial f}{\partial \boldsymbol{\sigma}}\right)^{T} \mathbf{D}^{e} \frac{\partial f}{\partial \boldsymbol{\sigma}}}
\end{aligned}
$$

The term $-\left(\partial f / \partial \boldsymbol{\varepsilon}^{p}\right)^{T}(\partial f / \partial \boldsymbol{\sigma})$ in the denominator is referred to as the hardening modulus $H$. This term is considered only when we verify this code (see Appendix D). The physical meaning of this term is also explained in Appendix D. When $\phi$ and $c$ are functions of $\boldsymbol{\varepsilon}^{p}$, it is required to consider this term.

Discretization by finite elements and numerical methods for non-linear visco-elasticity and elasto-plasticity are presented in Appendix B and D, respectively. GeoFEM was verified by comparing its solutions with those obtained analytically or by using other analysis codes for fundamental and practical problems (Garatani et al., 2001b). Therefore, sufficient reliability was ensured on the fundamental feature as a finite element analysis of the developed code. We verified the non-linear visco-elasticity analysis and large deformation components that were developed in this research, as shown in Appendix B, by comparing solutions of GeoFEM with those obtained by using TEKTON (Melosh and Raefsky, 1980). In these codes, we used the same non-linear visco-elastic method as that of TEKTON; however, TEKTON does not include the Mohr-Coulomb plasticity. Therefore, we verified our implementation of plasticity with the 


$$
z \stackrel{\mathrm{x}}{\longrightarrow}
$$

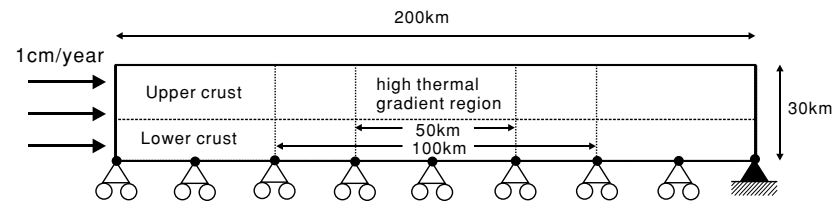

Fig. 1. Crust model and boundary conditions. We designate the crust as having a width of $200 \mathrm{~km}$ and depth of $30 \mathrm{~km}$. A grid interval is taken to be $0.5 \mathrm{~km}$. We apply a velocity to the left side of the crust and place the high-temperature area at the center of the crust. At the base of the crust we give boundary conditions that allow horizontal displacement.

Mohr-Coulomb criterion, as shown in Appendix D, by comparing its solutions with those obtained by using a commercial non-linear structural analysis software package FINAS (Iwata et al., 1982).

\section{Numerical Simulations of Deformation and Faulting Processes Beneath Northeastern Japan \\ 3.1 Tectonic background}

As an application of the developed FEM code, we consider the deformation and faulting processes beneath northeastern Japan. The Japanese island arc is a typical island arc which has various tectonic activities, including volcanism and the occurrence of large inland earthquakes. Shimamoto (1993) proposed a rheological model of the northeastern Japanese island arc using an estimated temperature distribution. In his model, the lithosphere is very thin (20 $\mathrm{km}$ ) because of hot geotherms and it undergoes large deformation.

Nakajima et al. (2001) estimated $P$-wave velocity $V_{p}, S$ wave velocity $V_{s}$, and $V_{p} / V_{s}$ structures beneath the northeastern Japan arc and revealed the existence of inclined seismic low-velocity zones in the mantle wedge sub-parallel to the subducted slab. In the lower crust, the areas with low $V_{p}$, low $V_{s}$, and high $V_{p} / V_{s}$ exist beneath the Ou Backbone Range. Hasegawa et al. (2005) developed a comprehensive model explaining the earthquake generation processes in northeastern Japan based on the results obtained from high-resolution observations. They considered that the inclined seismic low-velocity zone corresponds to the upwelling flow portion of subduction-induced convection. The upwelling flow transports aqueous fluids from the subducted slab up to shallow levels beneath the Ou Backbone Range. Beneath there, the temperature is also thought to be locally increased due to the upwelling flow. Because of the presence of aqueous fluid and high temperature beneath the Ou Backbone Range, crustal rock is weakened more than in the surrounding area. As a result, shortening deformation can occur in the lower crust beneath the Ou Backbone Range, which generates faulting in the upper crust. Miura et al. (2004) revealed the concentration of the horizontal east-west (EW) strain rate and uplift along the Ou Backbone Range. This observation on crustal deformation along the Ou Backbone Range can be explained by the model proposed by Hasegawa et al. (2005). Since this model is speculative, it requires verification through numer-
Table 1. Laboratory-measured elastic properties of crustal rock types.

\begin{tabular}{llccc}
\hline & Rock type & $V_{p}(\mathrm{~km} / \mathrm{s})$ & $v$ & $E(\mathrm{GPa})$ \\
\hline \multirow{2}{*}{ For the upper crust } & Granite & 6.07 & 0.24 & 81.7 \\
& Quartz diorite & 6.08 & 0.27 & 80.4 \\
& Felsic granulite & 6.25 & 0.27 & 85.5 \\
\hline \multirow{2}{*}{ For the lower crust } & Gabbro & 6.95 & 0.29 & 106 \\
& Mafic granulite & 6.86 & 0.31 & 103 \\
\hline
\end{tabular}

Values $V_{p}$ and $v$ are taken from the table in Holbrook et al. (1992).

ical simulations.

Tanaka and Ishikawa (2002) investigated the thermal gradient and heat flow in northeastern Japan and found that thermal gradient and heat flow is high at the Ou Backbone Range. The EW width of the thermal anomaly is 50-100 km. Furukawa (1995) estimated the temperature at the depth of $30 \mathrm{~km}$ throughout Japan and estimated the temperature at this depth beneath the Ou Backbone Range in northeastern Japan to be greater than $800^{\circ} \mathrm{C}$. Furukawa (1995) estimated the temperature at the depth of $30 \mathrm{~km}$ to be $600-400^{\circ} \mathrm{C}$ at the forearc region in northeastern Japan.

\subsection{Model and rheological structures}

We verify numerically the model proposed by Hasegawa et al. (2005) explaining the deformation and faulting processes beneath northeastern Japan using the developed FEM code. Let us consider a two-dimensional (2D) cross section of the crust that is $200 \mathrm{~km}$ long and $30 \mathrm{~km}$ thick, as shown in Fig. 1. We set the grid interval at $0.5 \mathrm{~km}$. The developed FEM code was construction for a 3D stress field. However, the code can be used for a $2 \mathrm{D}$ plane strain problem by adjusting the boundary conditions.

Our analysis includes elasto-plasticity with the MohrCoulomb criterion and non-linear visco-elasticity. The depth of the transition zone from elasto-plasticity to viscoelasticity is determined automatically using the yielding condition $f(\boldsymbol{\sigma})=0$. We set the parameters of the MohrCoulomb plasticity, the cohesion $c$, and the angle of internal friction $\phi$ to be $10 \mathrm{MPa}$ and $15^{\circ}$, respectively. The friction coefficient can be calculated as $\mu=\tan \phi \approx 0.27$, which is a relatively small value. Actually, Iio (1997) estimated the value of the friction coefficient on faults in a seismogenic zone to be around 0.2 from earthquake mechanism solutions.

We estimate the possible rocks in the upper and lower crusts from the velocity structure of the crust obtained by Iwasaki et al. (2001). They revealed an image of crustal and uppermantle structures across the northeastern Japan arc. In general, $P$-wave velocities of the upper crust and the lower crust are from 6.0 to $6.4 \mathrm{~km} / \mathrm{s}$ and from 6.5 to 7.0 $\mathrm{km} / \mathrm{s}$, respectively. Table 1 shows the laboratory-measured elastic properties of possible rocks for the upper crust and the lower crust beneath northeastern Japan. Granite, quartz diorite, and felsic granulite are candidates for rocks in the upper crust; gabbro and mafic granulite are candidates for rocks in the lower crust. Table 2 shows parameter values for crustal rock related to the flow law. The data on diabase are used instead of that on gabbro. In laboratory studies on flow laws, diabase is used because it has a finer grain size than 
Table 2. Flow properties of crustal rock types.

\begin{tabular}{cllccc}
\hline & Rock type & $A\left(\mathrm{MPa}^{-n} / \mathrm{s}\right)$ & $Q(\mathrm{~kJ} / \mathrm{mol})$ & $n$ & $\left.B(\mathrm{MPa} \mathrm{s})^{1 / n}\right)$ \\
\hline For the upper crust & Granite (wet) & $2.0 \times 10^{-4}$ & 137 & 1.9 & $2.75 \times 10^{1}$ \\
& Quartz diorite & $1.3 \times 10^{-3}$ & 219 & 2.4 & 4.89 \\
& Felsic granulite & $8.0 \times 10^{-3}$ & 243 & 3.1 & 1.44 \\
\hline \multirow{2}{*}{ For the lower crust } & Diabase (wet) & $2.0 \times 10^{-4}$ & 259 & 3.4 & 3.68 \\
& Mafic granulite & $1.4 \times 10^{4}$ & 445 & 4.2 & $3.08 \times 10^{-2}$ \\
\hline
\end{tabular}

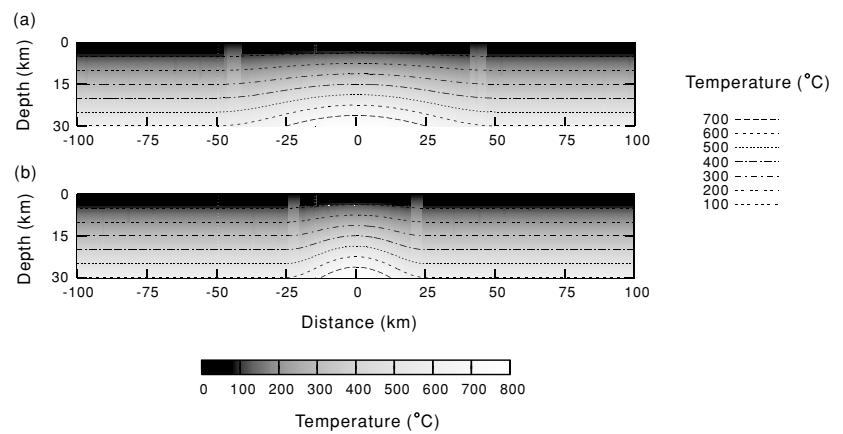

Fig. 2. Temperature distributions for two cases: a high-geothermal gradient region having characteristic widths $w_{h}$ of (a) $100 \mathrm{~km}$ and (b) $50 \mathrm{~km}$. The geothermal gradient is assumed to be $26.7^{\circ} \mathrm{C} / \mathrm{km}$ in the center of the model and $20.0^{\circ} \mathrm{C} / \mathrm{km}$ in the surrounding region.
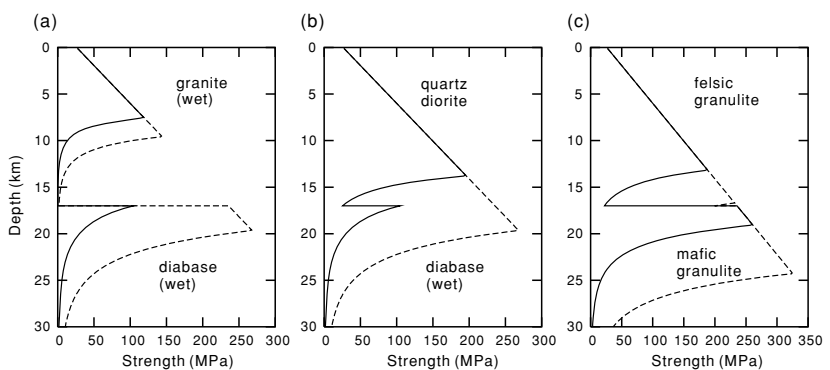

Fig. 3. Strength profiles for the crust with various rock types. The thermal gradient is assumed to be $26.7^{\circ} \mathrm{C} / \mathrm{km}$ (solid lines) and $20.0^{\circ} \mathrm{C} / \mathrm{km}$ (dashed lines). The strain rate is assumed to be $10^{-15} / \mathrm{s}$. (a) Granite for the upper crust and wet diabase for the lower crust. (b) Quartz diorite for the upper crust and wet diabase for the lower crust. (c) Felsic granulite for the upper crust and mafic granulite for the lower crust. gabbro and is appropriate for experimental studies. The parameter values, $A_{D}, Q$, and $n$ for crustal rocks, are taken from the table developed by Ranalli (1995). We translate a triaxial experimental constant $A_{D}$ into a plane-strain preexponential parameter value $B$ (Tullis et al., 1991; Ellis et al., 2001).

By considering a high-geothermal gradient region beneath the Ou Backbone Range, we set a high-geothermal gradient region in the center of the model. The geothermal gradient $g$ smoothly varies using a sinusoidal function of horizontal distance $x: g(x)=g_{0}+\left(g_{\max }-\right.$ $\left.g_{0}\right)\left\{\cos \left(2 \pi x / w_{h}\right)+1\right\} / 2$ for $|x| \leq w_{h} / 2$ and $g(x)=g_{0}$ for $|x|>w_{h} / 2$, where $g_{0}$ is the geothermal gradient of the surrounding region, $g_{\max }$ is the maximum geothermal gradient in the center of the model, and $w_{h}$ is the width characterizing a high-geothermal gradient region. The $w_{h}$ value is assumed to be $100 \mathrm{~km}$ and $50 \mathrm{~km}$. For a standard temperature distribution, the geothermal gradient is assumed to be $26.7^{\circ} \mathrm{C} / \mathrm{km}$ in the center of the model and $20.0^{\circ} \mathrm{C} / \mathrm{km}$ in the surrounding region. Figure 2 shows contour maps of the temperature distributions for two cases: high-thermal gradient regions having widths $w_{h}$ of $100 \mathrm{~km}$ and $50 \mathrm{~km}$, respectively. The coefficient $\eta$ is a function of water fugacity $f_{\mathrm{H}_{2} \mathrm{O}}$ (Kohlstedt et al., 1995). However, we do not consider the effect of water fugacity $f_{\mathrm{H}_{2} \mathrm{O}}$ because its effect has not been examined for rock types considered in the present study.

For comparison purposes, in Fig. 3, we show the strength profiles of the upper crust $(0-17 \mathrm{~km})$ and the lower crust $(17-30 \mathrm{~km})$ for various crustal rocks with a strain rate of $10^{-15} / \mathrm{s}$. The geothermal gradient is assumed to be $26.7^{\circ} \mathrm{C} / \mathrm{km}$ or $20.0^{\circ} \mathrm{C} / \mathrm{km}$. We consider three cases: wet granite for the upper crust and wet diabase for the lower crust; quartz diorite for the upper crust and wet diabase for the lower crust; felsic granulite for the upper crust and mafic granulite for the lower crust. In all cases, a weak viscous zone appears at the bottom of the upper crust and a strong viscous or plastic zone appears at the top of the lower crust with the geothermal gradient of $26.7^{\circ} \mathrm{C} / \mathrm{km}$. In the case of a wet granite upper crust (Fig. 3(a)), the depth of the plasticviscous transition zone becomes shallower than $10 \mathrm{~km}$, even for the geothermal gradient of $20.0^{\circ} \mathrm{C} / \mathrm{km}$.

Table 3 summarizes the crustal rock types and parameters for the geothermal structure in the investigated cases. In cases 1-5, we consider a crust that consists of a wet diabase to investigate the effects of spatial changes in the geothermal gradient in the horizontal direction. We then investigate the effects of the crustal compositions. Since the crustal composition is not uniquely constrained in northeastern Japan, we consider the possible rocks for the upper and lower crusts. We consider three crustal models (cases 6-8), which consists of two different rock types for the upper crust and lower crust, as shown in Table 2.

\subsection{Numerical results}

We first generate an initial equilibrium stress state, accounting for the effective stress law for the viscoelastic deformation and the Mohr-Coulomb criterion. When we consider the equilibrium static stress state, the effective stresses $\sigma_{x x}^{e f f}$ and $\sigma_{z z}^{e f f}$ should be $\rho_{r} g z-P_{f}$ where $\rho_{r}$ is the density of rock, $g$ is the acceleration due to gravity, $z$ is a depth, and $P_{f}$ is a pore fluid pressure. Assuming $P_{f}=\rho_{w} g z$, where $\rho_{w}$ is the density of water, $\sigma_{x x}^{e f f}=\sigma_{z z}^{e f f}=\left(\rho_{r}-\rho_{w}\right) g z$. To achieve this stress state, we first add the body force $\left(\rho_{r}-\rho_{w}\right) g$ to the bottom of the crust, where $\rho_{r}=3000$ $\mathrm{kg} / \mathrm{m}^{3}$ and $\rho_{w}=1000 \mathrm{~kg} / \mathrm{m}^{3}$. After the body force due 
Table 3

\begin{tabular}{cccccc}
\hline & $\begin{array}{c}\text { Rock type for the upper crust } \\
0 \leq z \leq 17(\mathrm{~km})\end{array}$ & $\begin{array}{c}\text { Rock type for the lower crust } \\
17 \leq z \leq 30(\mathrm{~km})\end{array}$ & $\begin{array}{c}w_{h} \\
(\mathrm{~km})\end{array}$ & $\begin{array}{c}g_{\max } \\
\left({ }^{\circ} \mathrm{C} / \mathrm{km}\right)\end{array}$ & $\begin{array}{c}g_{0} \\
\left({ }^{\circ} \mathrm{C} / \mathrm{km}\right)\end{array}$ \\
\hline Case 1 & Diabase (wet) & Diabase (wet) & 100 & 26.7 & 20.0 \\
Case 2 & Diabase (wet) & Diabase (wet) & 50 & 26.7 & 20.0 \\
Case 3 & Diabase (wet) & Diabase (wet) & 100 & 20.0 & 16.7 \\
Case 4 & Diabase (wet) & Diabase (wet) & 100 & 26.7 & 23.3 \\
Case 5 & Diabase (wet) & Diabase (wet) & 100 & 26.7 & 25.0 \\
Case 6 & Granite (wet) & Diabase (wet) & 100 & 26.7 & 20.0 \\
Case 7 & Quartz diorite & Diabase (wet) & 100 & 26.7 & 20.0 \\
Case 8 & Felcic granulite & Mafic granulite & 100 & 26.7 & 20.0 \\
\hline
\end{tabular}

$z$ : depth, $w_{h}$ : the width characterizing a high-geothermal gradient region, $g_{\max }$ : the maximum geothermal gradient in the center of the model, $g_{0}$ : the geothermal gradient in the surrounding region.

to gravity is added, viscous deformation is generated by time evolution to build up a uniform stress field. We subsequently apply a contracting displacement to the left side of the crust. In this way, we approximately consider the effective stress law.

The horizontal EW strain rate on the surface along the strain concentration zone is estimated to be of order of $10^{-7}$ /year from GPS observations (Miura et al., 2004). Considering a 50- to $100-\mathrm{km}$ deformation zone, the relative contractional velocity is determined to be $0.5-1 \mathrm{~cm} /$ year. Consequently, we apply a contracting displacement with a velocity of $1 \mathrm{~cm} /$ year to the left side of the crust. In almost all cases, the duration of applying the displacement boundary condition is $2.5 \times 10^{5}$ years so that the amount of contraction is $2.5 \mathrm{~km}$. During this duration, the stress state reaches a steady state following which there is no significant change. As such, this duration is sufficient to verify the deformation style.

3.3.1 One-layer crust Figure 4 shows the results for the case where the width $w_{h}$ characterizing a highgeothermal gradient region is $100 \mathrm{~km}$ (case 1). The geothermal gradient is assumed to be $26.7^{\circ} \mathrm{C} / \mathrm{km}$ in the center of the model and $20.0^{\circ} \mathrm{C} / \mathrm{km}$ in the surrounding region. An elapsed time from the beginning of contraction is $2.5 \times 10^{5}$ years so that the amount of contraction is $2.5 \mathrm{~km}$. Figure 4(a)-(d) shows the equivalent stress, the equivalent viscous strain for the deviatoric components of viscous strain, the equivalent plastic strain for the deviatoric components of plastic strain, and the equivalent total strain for the deviatoric components of total strain, respectively. We can confirm that shortening deformation occurs in the lower crust because of viscous nonlinear flow (Fig. 4(b)). As shown in Fig. 4(c), because of the Mohr-Coulomb plasticity in the upper crust, two dipping shear faults are generated from both upper edges of the highly shortening deformation zone in the lower crust. It should be noted that we can also observe the creation of a horizontal plastic deformation zone just above the highly contracted zone in the lower crust. This zone is created when the highly contracted zone is sufficiently wide. The equivalent stress is high along the bottom of the plastic region (Fig. 4(a)); however, it is almost uniform horizontally since the stress concentration caused by the shortening deformation in the lower crust is released by plastic deformation in the upper crust.

Figure 5 shows the results for case 2 after an elapsed time of $2.5 \times 10^{5}$ years. In this case only, a high-thermal gradient region has a width $w_{h}$ of $50 \mathrm{~km}$. As in the previous case, two dipping plastic deformation zones appear in the upper crust. Figure 6 shows the results for case 3 after an elapsed time of $2.5 \times 10^{5}$ years. In case $3, w_{h}$ is set as $100 \mathrm{~km}$, and the geothermal gradient is assumed to be $20.0^{\circ} \mathrm{C} / \mathrm{km}$ in the center of the model and $16.7^{\circ} \mathrm{C} / \mathrm{km}$ in the surrounding region. In this case, the depth of the plastic-viscous transition zone is deeper than that of case 1 , although the pattern of plastic deformation is almost identical to that of case 1 .

Figure 7 shows the equivalent total strain for the deviatoric components of total strain for cases 1,4 , and 5 . The geothermal gradient at the center of the model is $26.7^{\circ} \mathrm{C} / \mathrm{km}$ for all three cases. However, the geothermal gradient in the surrounding region is $20.0^{\circ} \mathrm{C} / \mathrm{km}, 23.3^{\circ} \mathrm{C} / \mathrm{km}$, and $25.0^{\circ} \mathrm{C} / \mathrm{km}$ for cases 1,4 , and 5 , respectively. At a depth of $30 \mathrm{~km}$, the difference in temperatures between the center of the model and the surrounding region is $200^{\circ} \mathrm{C}, 100^{\circ} \mathrm{C}$, and $50.0^{\circ} \mathrm{C}$ for cases 1,4 , and 5 , respectively. In cases 4 and 5 , a shortening deformation occurs in the lower crust because of a viscous nonlinear flow. However, in cases 4 and 5, the degree of localization is considerably smaller than that in case 1. As a result, the plastic deformation zones in the upper crust in cases 4 and 5 are less localized than that in case 1 . The differences in temperatures between the center of the model and the surrounding region in the lower crust determine the degree of localization in both the shortening deformation zone in the lower crust and the plastic deformation zone in the upper crust.

3.3.2 Two-layer crust In case 6, we consider a twolayer crust: a wet granite layer for the upper crust and a wet diabase layer for the lower crust. The geothermal gradient is assumed to be $26.7^{\circ} \mathrm{C} / \mathrm{km}$ in the center of the model and $20.0^{\circ} \mathrm{C} / \mathrm{km}$ in the surrounding region. Figure 8 shows the results after an elapsed time of $1.9 \times 10^{5}$ years. For an elapsed time greater than $2.0 \times 10^{5}$ years, numerical instability occurred due to the viscosity at the lower part of the upper crust being significantly low and the time step not being considerably small. Although the amount of contraction is $1.9 \mathrm{~km}$, it is adequate for obtaining an understanding of the deformation style. In this case, there is a viscous zone 
(a)

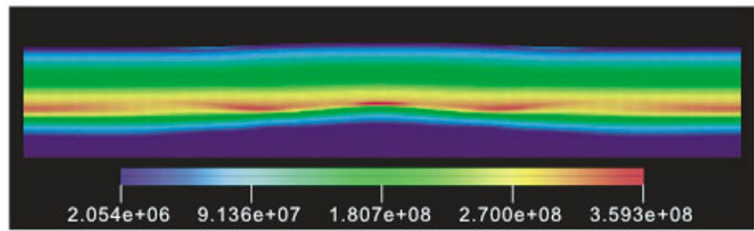

(b)

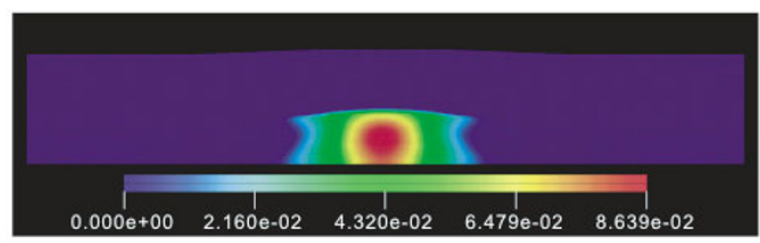

(c)

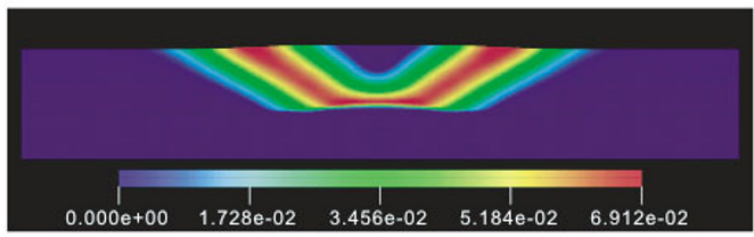

(d)

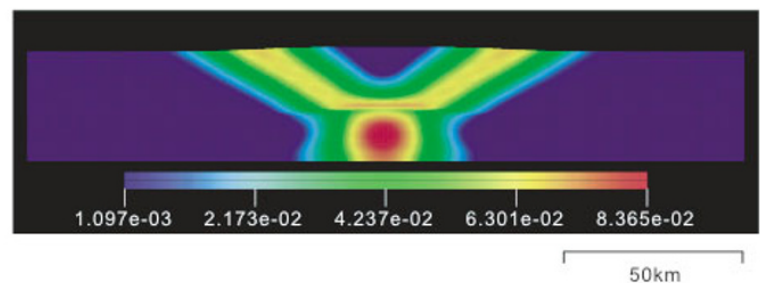

Fig. 4. Results for case $1\left(2.5 \times 10^{5}\right.$ years later). (a) Equivalent stress defined as $\bar{\sigma}=\sqrt{3 \sigma_{i j}^{\prime} \sigma_{i j}^{\prime} / 2}$. Stress is expressed in pascals (Pa). (b) Equivalent viscous strain defined as $\bar{\varepsilon}^{v}=\sqrt{3 \varepsilon_{i j}^{\prime v} \varepsilon_{i j}^{\prime v} / 2}$ for the deviatoric components of viscous strain. (c) Equivalent plastic strain defined as $\bar{\varepsilon}^{p}=\sqrt{3 \varepsilon_{i j}^{\prime p} \varepsilon_{i j}^{\prime p} / 2}$ for the deviatoric components of plastic strain. (d) Equivalent total strain defined as $\bar{\varepsilon}=\sqrt{3 \varepsilon_{i j}^{\prime} \varepsilon_{i j}^{\prime} / 2}$ for the deviatoric components of total strain. Viscous, plastic, and elastic strains are included in the total strain. The deformation scale in each panel is 1:1.

at the lower part of the upper crust and a thin plastic zone at the upper part of the lower crust. The depth of the plasticviscous transition zone in the upper crust is shallower than $10 \mathrm{~km}$. This is inconsistent with observations of the cut-off depth of seismicity.

In case 7, we consider a two-layer crust: a quartz diorite layer for the upper crust and wet diabase layer for the lower crust. Figure 9 shows the results after an elapsed time of $2.5 \times 10^{5}$ years. The depth of the plastic-viscous transition zone in the upper crust is around $14 \mathrm{~km}$ in the center of the model. Shortening deformation occurs in the lower part of the crust in the center of the model. There is a weak viscous zone in the lower part of the upper crust, which is sandwiched between two strong zones. Strength is high and stress is concentrated along the plastic-viscous transition zone in the upper crust and along the upper part of the lower crust. A thin plastic deformation region appears at the upper part of the lower crust in the center of the model.

In case 8 , we consider a two-layer crust: a felsic granulite layer for the upper crust and a mafic granulite layer for the lower crust. Figure 10 shows the results after an elapsed time of $2.5 \times 10^{5}$ years. In this case, we obtain almost identical results to those for case 7 . However, the plastic (a)

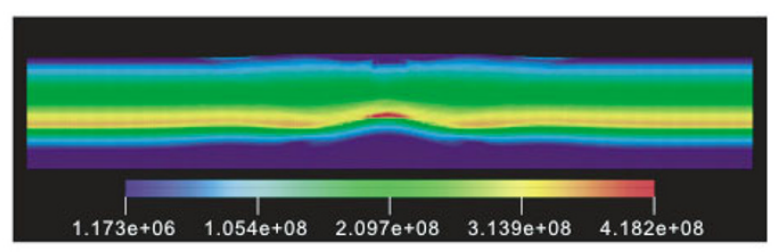

(b)

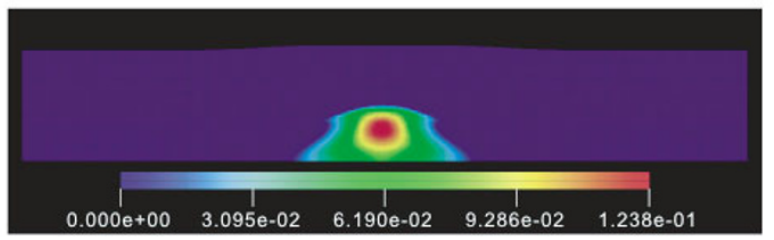

(c)

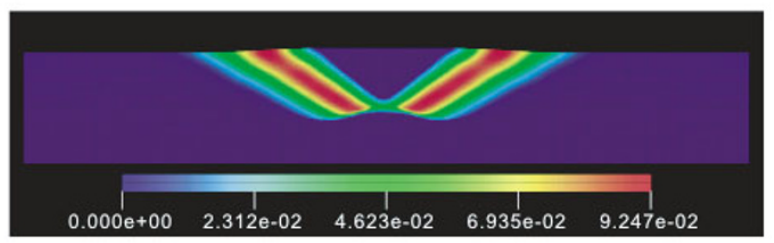

(d)

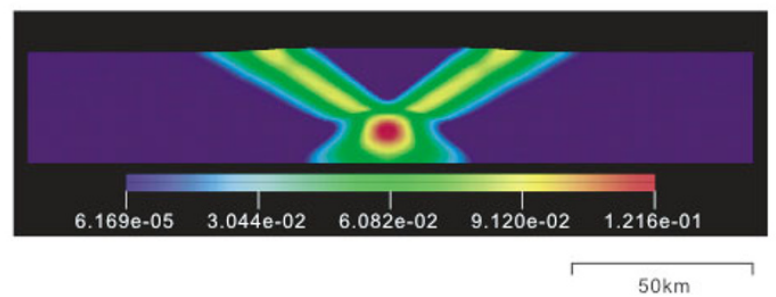

Fig. 5. As in Fig. 4, but for case 2.

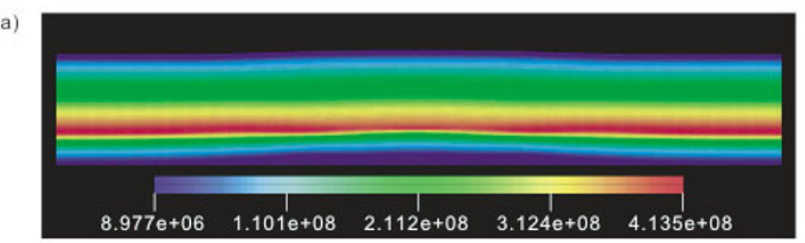

(b)

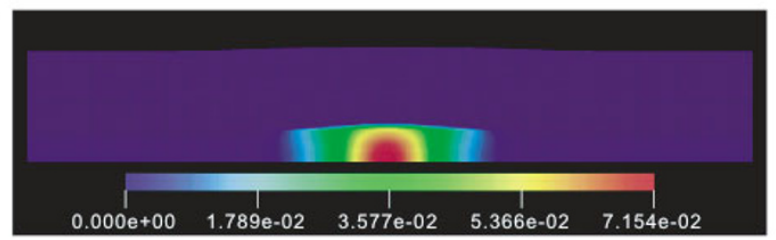

(c)

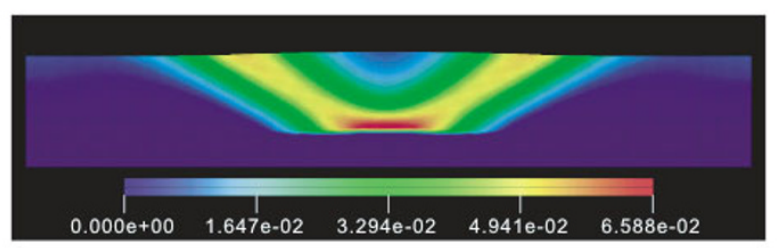

(d)

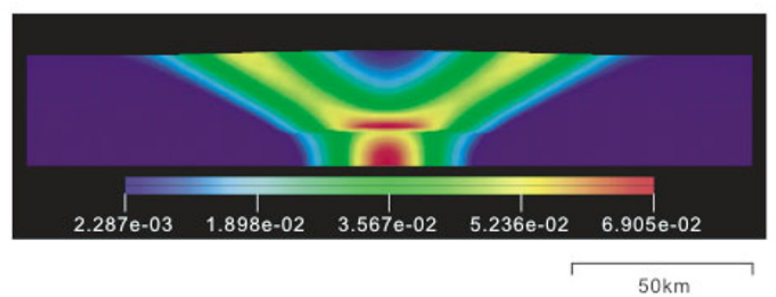

Fig. 6. As in Fig. 4, but for case 3. 
(a)

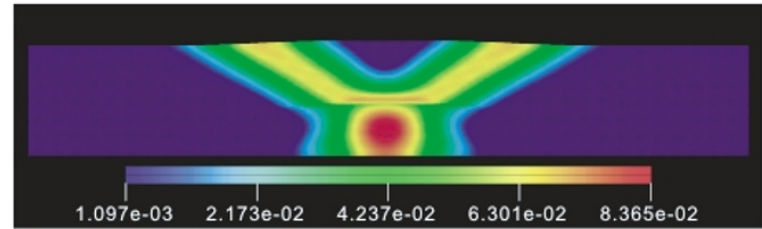

(b)

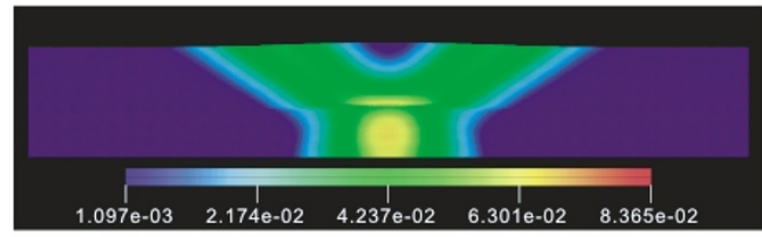

(c)

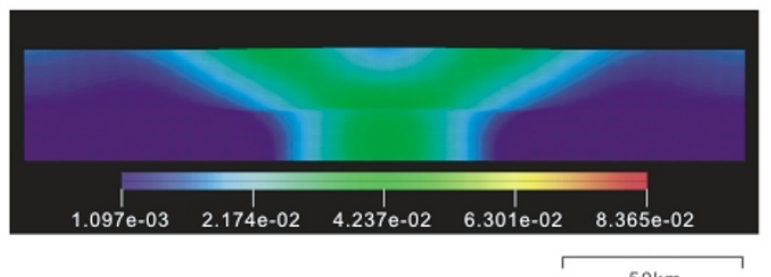

Fig. 7. Equivalent total strain defined as $\bar{\varepsilon}=\sqrt{3 \varepsilon_{i j}^{\prime} \varepsilon_{i j}^{\prime} / 2}$ for the deviatoric components of total strain $\left(2.5 \times 10^{5}\right.$ years later) for (a) case 1 , (b) case 4 , and (c) case 5 .

strength of the upper part of the lower crust is stronger than that of case 7 . Consequently, a very high stress region appears at the upper part of the lower crust in the center of the model.

Figure 11 shows the evolutions in the equivalent stress for case 7 from the beginning of the shortening deformation. Before the formation of the plastic zone, two dipping regions of high equivalent stress appear in the upper crust; around these regions, a plastic zone appears with the increase in shortening deformation. Once the plastic zones are well-developed, the two dipping regions of the high equivalent stress disappear. Stress is released because of plastic deformation. This feature of the time evolution of stress during the formation of the plastic zone is common for other cases. However, the final stress distribution depends on the strength profile of each case.

Figure 12 shows the viscous shear strain $\varepsilon_{x z}^{v}$ distribution and plastic shear strain $\varepsilon_{x z}^{p}$ distribution for case 8 . This confirms that the horizontal shear zones are developed at the bottom of the upper crust. A strong plastic zone exists at the upper part of the lower crust and a weak, viscous zone exists at the bottom of the upper crust. Based on these findings, the horizontal shear zones that developed at the bottom of the upper crust are thought to result from the different viscosities of the two different rheological materials. The results obtained in case 7 are similar to those shown in Fig. 12 for case 8; however, in the latter, we can confirm the developed horizontal shear zones more clearly.

3.3.3 Activation of an existing fault During the Miocene, numerous active faults were formed in northeastern Japan as low-angle normal faults with the back arc opening. These faults have been reactivated because of the shortening deformation by the inversion processes occurring since the late Neogene (Sato et al., 2004). One of

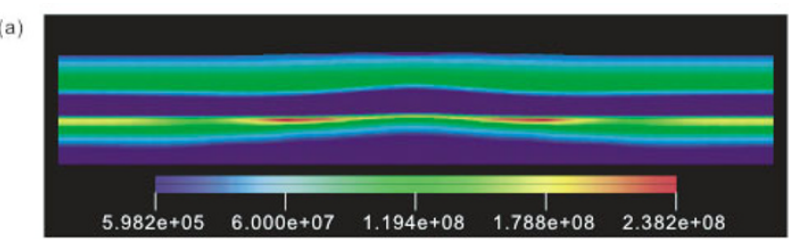

(b)

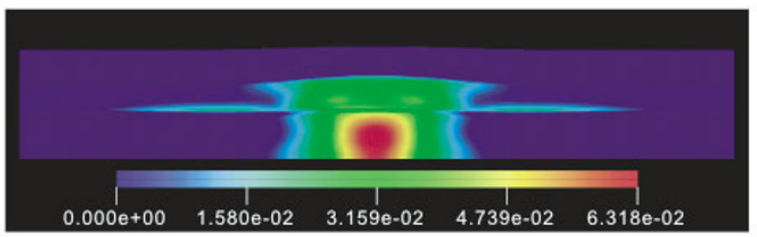

(c)

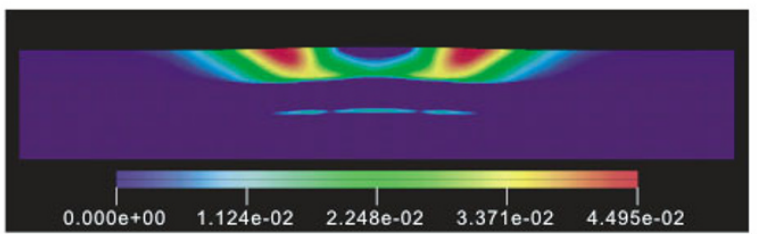

(d)

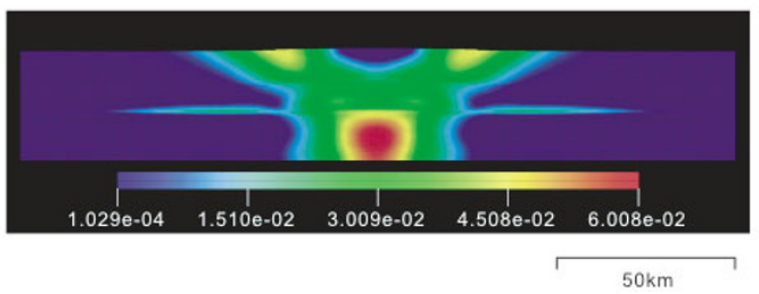

Fig. 8. As in Fig. 4, but for case 6 and for distributions $1.9 \times 10^{5}$ years later.

(a)

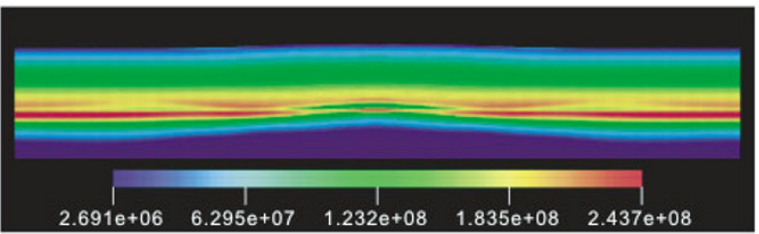

(b)

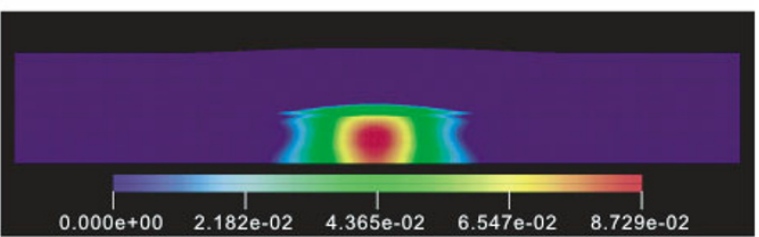

(c)

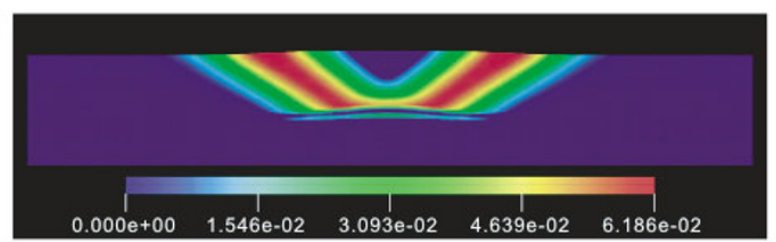

(d)

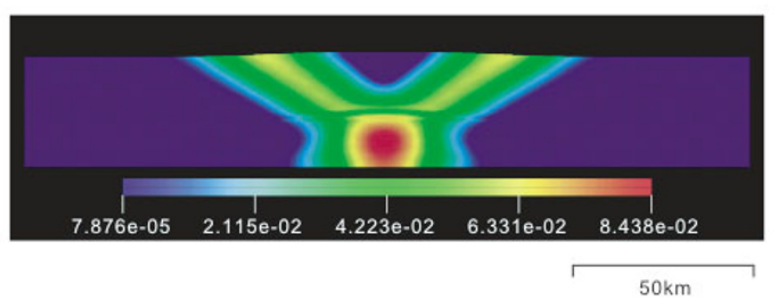

Fig. 9. As in Fig. 4, but for case 7. 
(a)

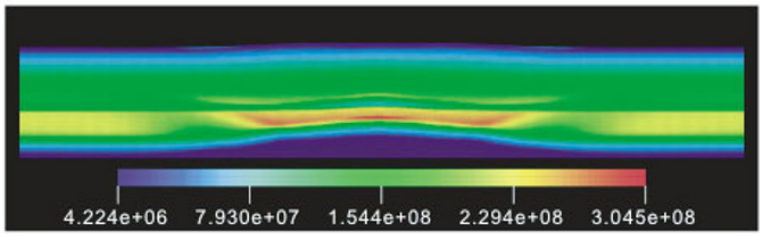

(b)

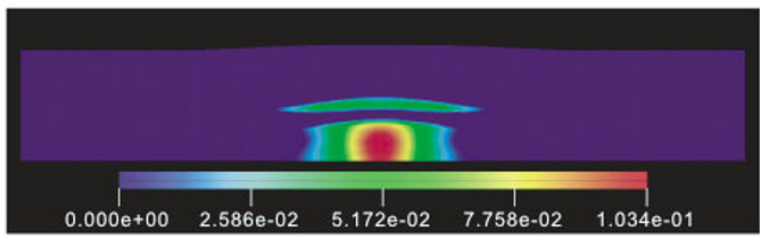

(c)

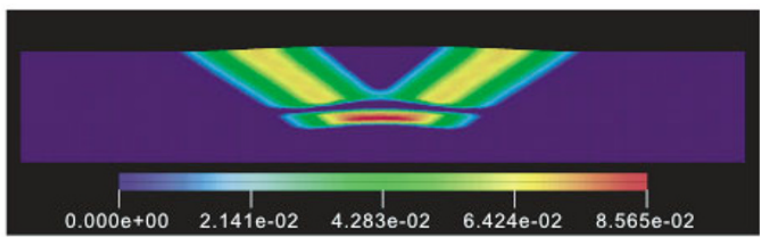

(d)

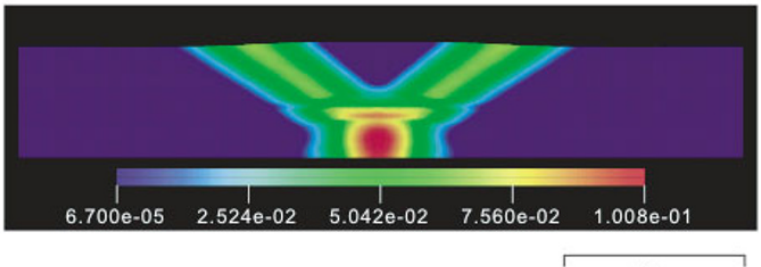

Fig. 10. As in Fig. 4, but for case 8 .

(a)

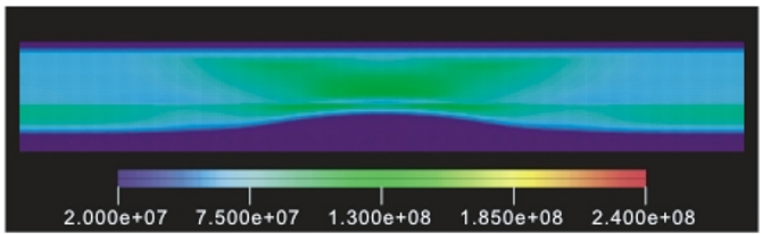

(b)

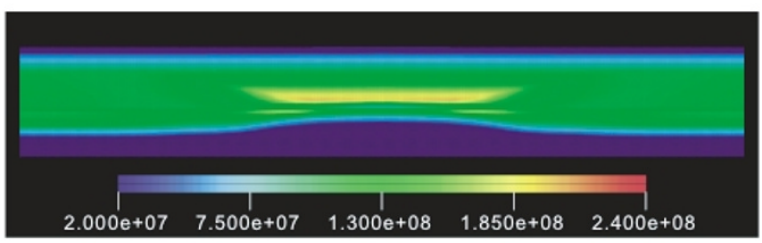

(c)

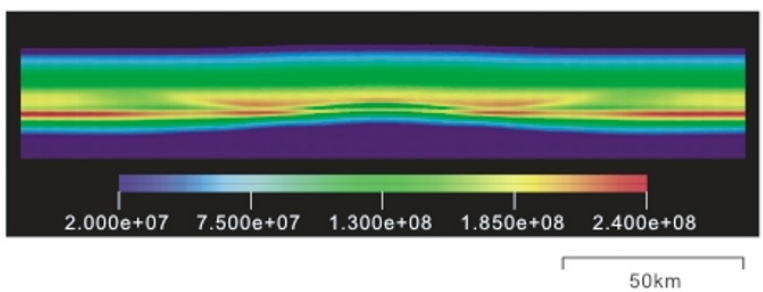

Fig. 11. Evolution of equivalent stress for case 7. Stress is expressed in pascals $(\mathrm{Pa})$. (a) Equivalent stress $2.5 \times 10^{4}$ years later. (b) Equivalent stress $5.0 \times 10^{4}$ years later. (c) Equivalent stress $2.0 \times 10^{5}$ years later.

the more important questions is which of the existing faults is being reactivated during shortening deformation. Therefore, it is necessary to consider the existing dipping faults. If the lower crust is very weak, dipping faults are easy to activate. However, in the case where the lower crust is not so weak, it is difficult for the existing faults to activate since (a)

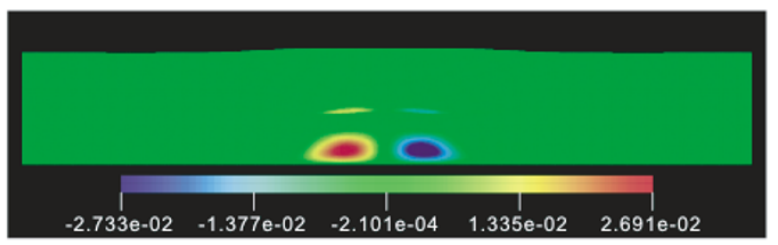

(b)

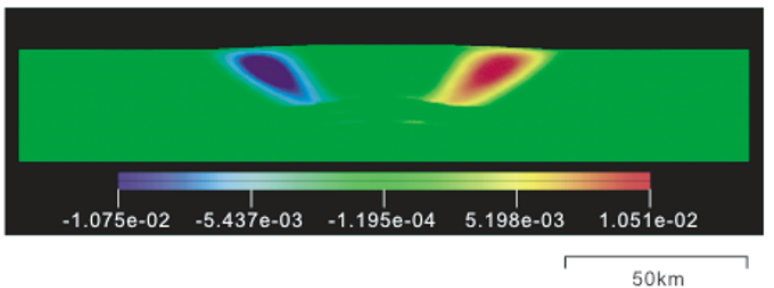

Fig. 12. Components for shear strains for case 8. (a) Viscous shear strain $\varepsilon_{x z}^{v}$ distribution $\left(2.5 \times 10^{5}\right.$ years later $)$. (b) Plastic shear strain $\varepsilon_{x z}^{p}$ distribution $\left(2.5 \times 10^{5}\right.$ years later $)$.

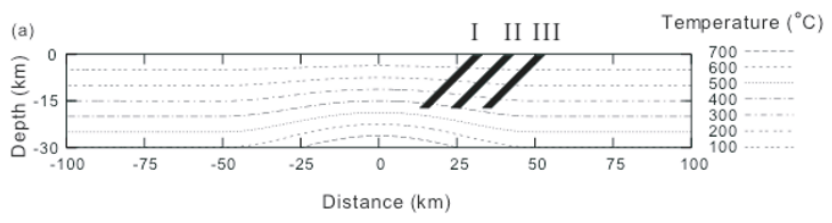

(b)

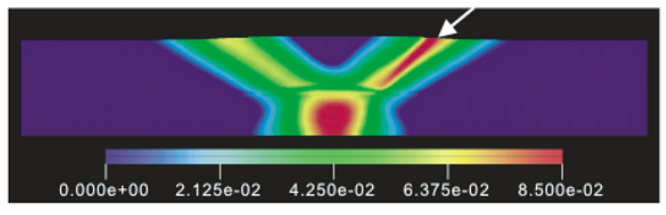

(c)
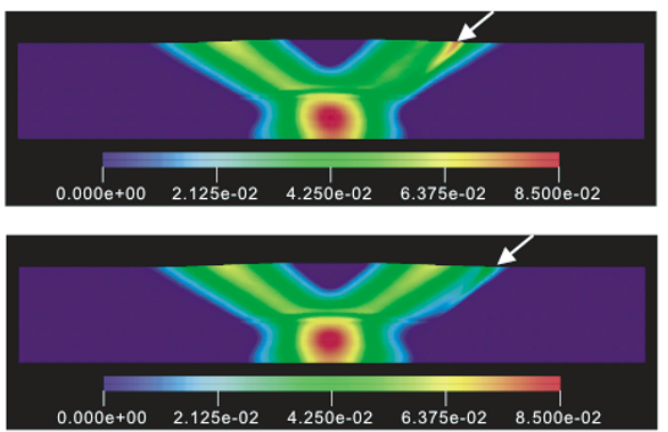

Fig. 13. Effect of an existing fault in the upper crust. The location of the existing faults in the upper crust are indicated by the shaded zones for three cases, cases I-III (a). The equivalent strain distribution $\left(2.5 \times 10^{5}\right.$ years later) is shown for three cases; (b) case I, (c) case II, and (d) case III. The locations of the existing faults are indicated by the white arrows.

the upper part of the lower crust does not deform easily. We examine the manner in which the existing weak fault zone is activated.

Similar to case 7, we consider a two-layer crust: a quartz diorite layer for the upper crust and a wet diabase layer for the lower crust. We also consider three different locations of the weak fault zone in the upper crust, as shown in Fig. 13(a). The cohesion inside the weak fault zone is $2 \mathrm{MPa}$ while that outside of this zone is $10 \mathrm{MPa}$. The dip angle of a weak fault zone is $45^{\circ}$, and the width of weak zone is set at $2.12 \mathrm{~km}$. Figure 13(b)-(d) shows the results for three cases. If the weak fault zone exists in the same region where a large plastic deformation appears, 
the fault zone is activated (Fig. 13(b)). However, if the weak fault zone exists far from the large plastic deformation region, the fault zone is not activated (Fig. 13(d)). These numerical results suggest that where a weak lower crustal anomaly exists, such as beneath the Ou Backbone Range, activation of the existing fault zones is controlled by the flow deformation process in the lower crust.

\section{Discussion and Conclusions}

To simulate the deformation and faulting processes in the crust, we used non-linear FEM codes that were developed based on the GeoFEM platform, which includes functions of non-linear viscoelasticity, plasticity, and the approximate analysis for large deformation. We checked out our FEM codes by comparing our results with those obtained using TEKTON and a commercial software package, FINAS.

Hasegawa et al. (2005) developed a model of crustal deformation in which shortening deformation in the lower crust occurs in the weak zone beneath the Ou Backbone Range, with this deformation causing shear faulting in the upper crust. To verify their model we performed numerical simulations of crustal deformation that occurs beneath northeastern Japan. We set a high-thermal gradient region in the center of the one-layer crust model that consists of a wet diabase. When contracting displacement is applied, shortening deformation occurs in the lower crust due to viscous nonlinear flow. Because of the Mohr-Coulomb plasticity in the upper crust, two dipping shear faults are generated from both upper edges of the highly shortening deformation zone in the lower crust. We were able to observe the creation of a horizontal plastic deformation zone just above the highly shortening deformation zone in the lower crust. The differences in temperatures between the center of the model and the surrounding region in the lower crust determine the degree of localization in both the shortening deformation zone in the lower crust and the plastic deformation zone in the upper crust.

To examine the effects of crustal material we investigated three cases of a two-layer crust: (1) wet granite for the upper crust and wet diabase for the lower crust; (2) quartz diorite for the upper crust and wet diabase for the lower crust; (3) felsic granulite for the upper crust and mafic granulite for the lower crust. In these cases, four different deformation zones appear: a plastic zone and viscous zone in the upper crust, and a plastic zone and viscous zone in the lower crust. In the case where we consider wet granite for the upper crust and wet diabase for the lower crust, the depth of the plastic-viscous transition zone in the upper crust is less than $10 \mathrm{~km}$. However, seismological observations show that the depth of the brittle-viscous transition zone is greater than $10 \mathrm{~km}$; therefore, wet granite is an inappropriate rock type for the upper crust in northeastern Japan. Nishimoto et al. (2005) recently carried out ultrasonic laboratory measurements of $P$-wave velocity $\left(V_{p}\right)$ up to $1.0 \mathrm{GPa}$ in the temperature range of $25-400^{\circ} \mathrm{C}$ for crustal and mantle xenoliths of Ichino-megata, northeastern Japan. The rocks used in their study are considered to be representative rock samples of the crust and upper mantle of the back arc side of the northeastern Japan arc. In their study, quartz diorite was expected to be the rock for the upper crust and the hornblende- pyroxene gabbro or the amphibolites for the lower crust. On the basis of their numerical and petrological studies, we can conclude that quartz diorite is a representative rock for the upper crust.

In the two-layer crust model, as in the one-layer crust model, shortening deformation caused by viscous flow can occur in the high-temperature region in the lower crust, resulting in the generation of shear faulting in the upper crust. These numerical results suggest that tectonic loading in the upper crust results from shortening deformation in the lower crust in northeastern Japan. Consequently, our results can explain the model developed by Hasegawa et al. (2005) based on observations.

During the Miocene, numerous active faults were formed in northeastern Japan as low-angle normal faults with the back arc opening; these faults have now been reactivated (Sato et al., 2004). The reactivation of existing faults is thought to be controlled by the shortening deformation in the low viscous zone in the lower crust. We have examined which existing weak fault zone has been reactivated. If the weak fault zone exists in the same region where large plastic deformation appears, the fault zone located in this region is activated. However, if the weak fault zone exists far from the high-geothermal gradient region, the fault zone is not activated. These numerical results suggest that for a setting analogous to the Ou Backbone Range, with a significant geothermal anomaly in the lower crust, the reactivation of the existing weak fault zone is controlled by a non-linear viscous flow in the low viscous region in the lower crust. These results are also consistent with the model developed by Hasegawa et al. (2005).

We consider the Nagamachi-Rifu fault as an example. Umino et al. (2002) found that a low- $V_{s}$ and high- $V_{p} / V_{s}$ area exists at depths of $20-40 \mathrm{~km}$ below the deeper extension of the Nagamachi-Rifu fault beneath the Ou Backbone Range. They suggest that it is caused by the presence of partially molten materials. Therefore, viscosity is thought to be lower around this region than in the surrounding regions. As a result, shortening deformation is thought to occur in the lower crust, resulting in a concentration of stress in the deeper part of the Nagamachi-Rifu fault.

We have presented the preliminary results of our simulations of the deformation processes occurring beneath northeastern Japan. Our model is simple; we consider only the layered structure of the crust and the effects of a hightemperature region in the crust in a compressional tectonic setting. As indicated in the model proposed by Hasegawa (2005), aqueous fluids are thought to be transported upward through the upwelling flow due to subduction-induced convection to reach shallow levels beneath the Backbone Range. These aqueous fluids weaken the crust both chemically and mechanically. Therefore, we need to consider the effects of aqueous fluids on crustal deformation. We also need to consider the effect of a subducting plate boundary and the $3 \mathrm{D}$ heterogeneous structure of the crust. Furthermore, we should consider the localization process of the viscous shear zone because of viscous dissipation, grain reduction, among others. The present finite element functions were developed based on the parallel finite element code, GeoFEM. Our finite element functions will be useful for re- 
alistic large computations of deformation in the lower crust and tectonic loading processes for large inland earthquakes in the future.

Acknowledgments. We referred to TEKTON to install the nonlinear visco-elasticity function and the approximated function for large deformation on the GeoFEM platform and used it to verify our codes. We thank Y. Iio, T. Sagiya, N. Shigematsu, and T. Iwasaki for their useful discussions. We are extremely thankful to S. Ellis, E. Hetland, and E. Fukuyama for their various thoughtful comments that significantly improve the manuscript. We also thank S. Miura, and Y. Ogawa for useful comments on this study. This study was supported by a grant from the Comprehensive Joint Research of the Special Coordination Funds for Promoting Science and Technology, "Comprehensive Research on Slip and Flow Processes in and below the Seismogenic Region". For this study, we used the computer systems of Earthquake Information Center of Earthquake Research Institute, University of Tokyo.

\section{Appendix A. Formulation for the approximate analysis for large deformation}

We describe the formulation for the approximate analysis for large deformation that was adopted by Garatani $e t$ al. (2003). The total Lagrange method refers to the initial configuration in Fig. A.1, whereas the updated Lagrange method refers to the updated configuration (current configuration) in Fig. A.1. Our method is based on the updated Lagrange method. The stress equation of equilibrium in Cartesian coordinates can be expressed as:

$$
\sigma_{i j, j}+q_{i}=0
$$

where $q_{i}$ stands for body forces. The natural (force) boundary conditions are

$$
\sigma_{i j} n_{j}=p_{i} \quad \text { on } \quad A_{\sigma} .
$$

The essential (displacement) boundary conditions are

$$
\Delta u_{i}=\overline{\Delta u}_{i} \quad \text { on } \quad A_{u} .
$$

The equilibrium equation is multiplied by the weighted function $w_{i}$ and is integrated over volume $V$ :

$$
\int_{V} w_{i}\left(\sigma_{i j, j}+q_{i}\right) d v=0 .
$$

By using Green's theorem and substituting Eq. (A.2) into Eq. (A.4), we obtain

$$
\begin{aligned}
\int_{V} w_{i, j} \sigma_{i j} d v= & \int_{V} w_{i} q_{i} d v+\int_{A_{\sigma}} w_{i} p_{i} d s \\
& +\int_{A_{u}} w_{i} \sigma_{i j} n_{j} d s .
\end{aligned}
$$

In order to satisfy the essential boundary conditions (A.3), we selected $\delta \Delta u_{i}$ that satisfies $\delta \Delta u_{i}=0$ on $A_{u}$ as a weighted function:

$$
\int_{V} \sigma_{i j} \delta \Delta u_{i, j} d v=\int_{V} q_{i} \delta \Delta u_{i} d v+\int_{A_{\sigma}} p_{i} \delta \Delta u_{i} d s .
$$

Therefore, we obtain the virtual work equation:

$$
\int_{V} \sigma_{i j} \delta \Delta \varepsilon_{i j} d v=\int_{V} q_{i} \delta \Delta u_{i} d v+\int_{A_{\sigma}} p_{i} \delta \Delta u_{i} d s .
$$

In the updated Lagrange method, we use Green's strain. Ignoring the second-order terms this strain becomes the infinitesimal strain defined in linear elasticity:

$$
\Delta \varepsilon_{i j} \approx \frac{1}{2}\left(\frac{\partial \Delta u_{i}}{\partial X_{j}}+\frac{\partial \Delta u_{j}}{\partial X_{i}}\right)
$$

where $X_{i}$ denotes the coordinates in the current configuration. We then obtain the incremental form of the virtual work equation for determining the configuration at time $t+\Delta t$, as shown in Fig. A.1. Since we refer to the current configuration, we need to use the nominal stress tensor increment $\Delta s_{i j}$. The nominal stress tensor $s_{i j}$ refers the current known configuration.

$$
\begin{aligned}
\int_{V}\left(\sigma_{i j}\right. & \left.+\Delta s_{i j}\right) \delta \Delta \varepsilon_{i j} d v \\
= & \int_{V}\left(q_{i}+\Delta q_{i}\right) \delta \Delta u_{i} d v \\
& +\int_{A_{\sigma}}\left(p_{i}+\Delta p_{i}\right) \delta \Delta u_{i} d s .
\end{aligned}
$$

Therefore,

$$
\begin{aligned}
\int_{V} \Delta s_{i j} \delta \Delta \varepsilon_{i j} d v= & \int_{V} \Delta q_{i} \delta \Delta u_{i} d v \\
& +\int_{A_{\sigma}} \Delta p_{i} \delta \Delta u_{i} d s+\delta R \\
\delta R=\int_{V} q_{i} \delta \Delta u_{i} d v & +\int_{A_{\sigma}} p_{i} \delta \Delta u_{i} d s-\int_{V} \sigma_{i j} \delta \Delta \varepsilon_{i j} d v .
\end{aligned}
$$

If the deformation is very small for one step, the nominal stress tensor increment can be regarded as the Cauchy stress increment:

$$
\Delta s_{i j}=\Delta \sigma_{i j}-\sigma_{i k} \frac{\partial \Delta u_{i}}{\partial X_{k}}-\sigma_{i j} \frac{\Delta \rho}{\rho} \approx \Delta \sigma_{i j} .
$$

We then obtain the following equation:

$$
\begin{aligned}
\int_{V} \Delta \sigma_{i j} \delta \Delta \varepsilon_{i j} d v= & \int_{V} \Delta q_{i} \delta \Delta u_{i} d v \\
& +\int_{A_{\sigma}} \Delta p_{i} \delta \Delta u_{i} d s+\delta R
\end{aligned}
$$

Constitutive laws must be independent of the reference frame so that the Jaumann stress rate, which is objective, is used in the laws. The Jaumann stress rate is expressed using the spin rate tensor, which represents the angular velocity of the material. In our analysis, the amount of the angular velocity of material for one step is very small. For that reason, constitutive laws can be expressed using the Cauchy stress.

Following the formulation of finite elements, we discretize Eq. (A.12) and obtain the following equation:

$$
\mathbf{K} \Delta \mathbf{u}=\Delta \mathbf{P}+\mathbf{R}
$$

where $\mathbf{K}$ is the stiffness matrix, $\Delta \mathbf{u}$ is a vector of incremental nodal point displacements, $\Delta \mathbf{P}$ is a vector of the incremental applied load:

$$
\begin{aligned}
& \mathbf{K}=\int_{V} \mathbf{B}^{T} \mathbf{D} \mathbf{B} d v \\
& \Delta \mathbf{P}=\int_{V} \mathbf{N}^{T} \mathbf{N} \Delta \mathbf{q} d v+\int_{V} \mathbf{N}^{T} \mathbf{N} \Delta \mathbf{p} d s \\
& \mathbf{R}=\int_{V} \mathbf{N}^{T} \mathbf{N q} d v+\int_{V} \mathbf{N}^{T} \mathbf{N p} d s-\int_{V} \mathbf{B}^{T} \boldsymbol{\sigma} d v
\end{aligned}
$$




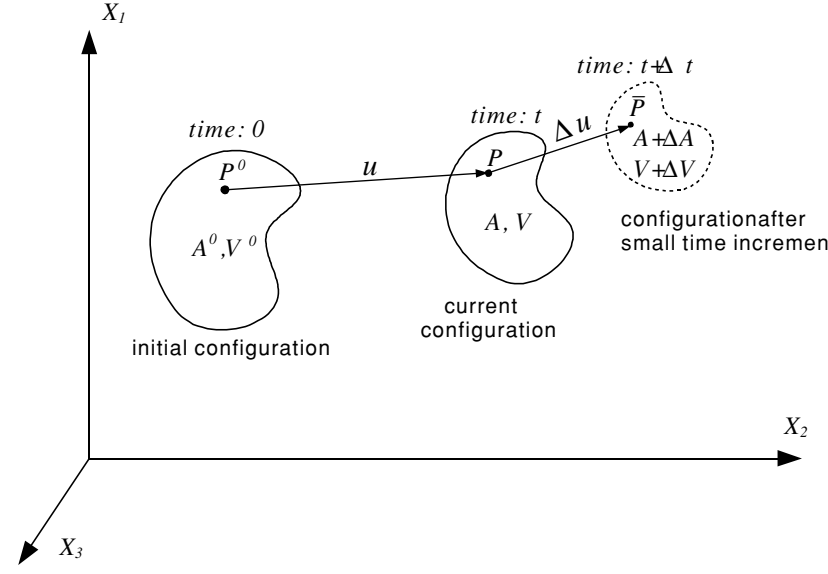

Fig. A.1. The initial configuration, current configuration, and configuration after a small time increment. The total Lagrange method refers to the initial configuration, whereas the updated Lagrange method refers to the current configuration. $V$ and $A$ indicate the volume and surface area of the deformable body in the current configuration.

Here, $\mathbf{B}$ is the strain-displacement matrix, $\mathbf{D}$ is the stressstrain material property matrix, and $\mathbf{N}$ is the shape function.

\section{Appendix B. Numerical method for non-linear visco-elasticity}

Two methods exist for solving the non-linear viscoelastic problem using an incremental time scheme: the explicit and the implicit method. The details of algorithms are presented by Melosh and Raefsky (1980) and Zienkiewicz and Taylor (1994). The equation that should be solved is:

$$
\mathbf{K} \Delta \mathbf{u}=\Delta \mathbf{P}^{\prime}+\mathbf{R} \text {. }
$$

For the explicit method, $\mathbf{K}$ and $\Delta \mathbf{P}^{\prime}$ are defined as:

$$
\begin{aligned}
& \mathbf{K}=\int_{V} \mathbf{B}^{T} \mathbf{D}^{e} \mathbf{B} d v \\
& \Delta \mathbf{P}^{\prime}=\int_{V} \mathbf{B}^{T} \mathbf{D}^{e} \Delta t \boldsymbol{\beta}^{\prime} d v+\Delta \mathbf{P}
\end{aligned}
$$

where $\Delta t$ is a time step, and $\boldsymbol{\beta}^{\prime}$ is defined as $\partial \boldsymbol{\beta}(\boldsymbol{\sigma}) / \partial \boldsymbol{\sigma}$. $\boldsymbol{\beta}(\boldsymbol{\sigma})$ is the functional form of the stresses dependence $\dot{\boldsymbol{\varepsilon}}^{c}$ of defined in Eq. (3). For the implicit method, $\mathbf{K}$ and $\Delta \mathbf{P}^{\prime}$ are defined as:

$$
\begin{aligned}
& \mathbf{K}=\int_{V} \mathbf{B}^{T}\left(\mathbf{D}^{e^{-1}}+\alpha \Delta t \boldsymbol{\beta}^{\prime}\right)^{-1} \mathbf{B} d v \\
& \Delta \mathbf{P}^{\prime}=\int_{V} \mathbf{B}^{T}\left(\mathbf{D}^{e^{-1}}+\alpha \Delta t \boldsymbol{\beta}^{\prime}\right)^{-1} \Delta t \boldsymbol{\beta}^{\prime} d v+\Delta \mathbf{P}
\end{aligned}
$$

where $\alpha \in[0,1]$.

While the explicit method is easy to install and uses less memory and computational power, it is sometimes unusable and errors are amplified. A relatively small time step is required to satisfy the stable time limit (Zienkiewicz and Taylor, 1994). The implicit method has the opposite features: it is more difficult to install and involves many iterations per time step; however it is very stable and can have much larger time steps. The most effective method is selected depending on the features of the viscous model. In our code, we installed both the explicit and implicit schemes.

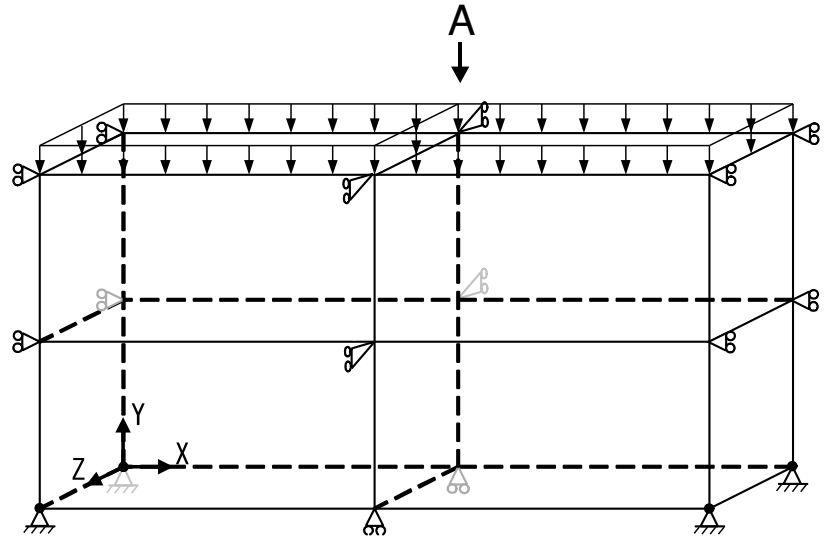

Fig. B.1. A four-element model and boundary conditions that are used to compare the results obtained using our code with those obtained using TEKTON and FINAS.

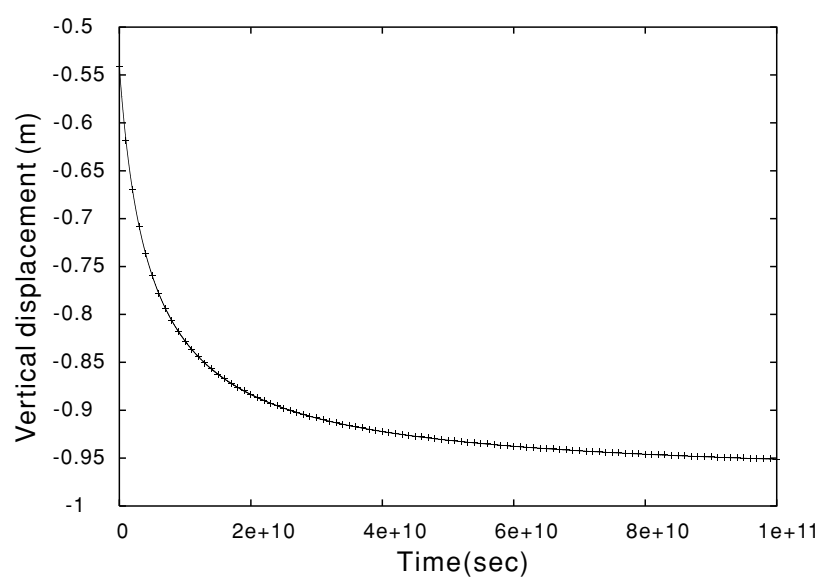

Fig. B.2. Comparison of solutions obtained using our code with those obtained by using TEKTON for a deformation problem in a non-linear visco-elastic material. A body force is applied at $t=0$ in the four-element model shown in Fig. B.1; this model consists of a non-linear visco-elastic material. The solid line and crosses show changes in vertical displacements with time at point A in Fig. B.1, which were obtained using our code and TEKTON, respectively.

Using this non-linear visco-elasticity analysis function and the approximate analysis for large deformation, we verified our code by solving a stabilized pressure field given by long-term vertical body force, applied in the visco-elastic crust, and confirmed that the results are the same as those obtained using TEKTON (Melosh and Raefsky, 1980). Let us consider a four-element model and the boundary conditions shown in Fig. B.1. We consider a non-linear viscoelastic material. A body force is applied at $t=0$. The magnitude of the body force is $\rho_{r} g$ where $\rho_{r}=2650 \mathrm{~kg} / \mathrm{m}^{3}$. We then examine how viscous deformation is generated by time evolution. We solve this problem with an implicit method using our code and TEKTON. We set the values of the viscosity $\eta, n$, Young's modulus $E$, and Poisson's ratio $v$ to be $3.162 \times 10^{13} \mathrm{~Pa} / \mathrm{s}^{2}, 2.0,8 \times 10^{2} \mathrm{GPa}$, and 0.25 , respectively. The displacements at point $\mathrm{A}$ for certain elapsed times are shown in Fig. B.2. The difference between our solutions and those obtained by using TEKTON is less than $0.02 \%$; therefore, our solutions are almost identical to those obtained using TEKTON. 
Appendix C. Derivation of the incremental elastoplastic constitutive relation

From Eqs. (2), (5), and (7), we obtain the following equation:

$$
d \boldsymbol{\varepsilon}=\mathbf{D}^{e^{-1}} d \boldsymbol{\sigma}+\lambda \frac{\partial f}{\partial \boldsymbol{\sigma}} .
$$

Therefore,

$$
d \boldsymbol{\sigma}=\mathbf{D}^{e}\left(d \boldsymbol{\varepsilon}-\frac{\partial f}{\partial \boldsymbol{\sigma}} \lambda\right)
$$

From Eqs. (7) and (8),

$$
\left(\frac{\partial f}{\partial \boldsymbol{\sigma}}\right)^{T} d \boldsymbol{\sigma}+\left(\frac{\partial f}{\partial \boldsymbol{\varepsilon}^{p}}\right)^{T} \lambda \frac{\partial f}{\partial \boldsymbol{\sigma}}=0
$$

From Eqs. (C.2) and (C.3), we can obtain $\lambda$ :

$$
\lambda=\frac{\left(\frac{\partial f}{\partial \boldsymbol{\sigma}}\right)^{T} \mathbf{D}^{e} d \boldsymbol{\varepsilon}}{-\left(\frac{\partial f}{\partial \boldsymbol{\varepsilon}^{p}}\right)^{T} \frac{\partial f}{\partial \boldsymbol{\sigma}}+\left(\frac{\partial f}{\partial \boldsymbol{\sigma}}\right)^{T} \mathbf{D}^{e} \frac{\partial f}{\partial \boldsymbol{\sigma}}} .
$$

By substituting Eq. (C.4) into Eq. (C.2), we obtain the incremental elasto-plastic constitutive relation (9)-(11).

\section{Appendix D. Numerical method for elasto- plasticity}

When plastic yielding occurs $(f(\boldsymbol{\sigma})=0)$, material behaves in an elasto-plastic manner. In this case, we solve the following equation:

$$
\mathbf{K} \Delta \mathbf{u}=\Delta \mathbf{P}+\mathbf{R}
$$

where the stiffness matrix $\mathbf{K}$ is expressed using the elastoplastic matrix $\mathbf{D}^{e p}$ defined in Eqs. (10) and (11);

$$
\mathbf{K}=\int_{V} \mathbf{B}^{T} \mathbf{D}^{e p} \mathbf{B} d v .
$$

Since $\mathbf{K}$ is a function of $\mathbf{u}$, we need to solve the non-linear equation. For solving this system, the Newton-Raphson method was used.

To verify our function for the plasticity with the MohrCoulomb criterion, we solved a simple uniaxial problem and compared the results with those obtained using a commercial nonlinear structural analysis software, FINAS (Iwata et al., 1982). Let us consider a four-element model as shown in Fig. B.1. In this case, we assume boundary conditions in a manner such that a uniaxial vertical stress occurs when we add negative vertical forces. We assume that strain hardening occurs after the yielding. In the case where no strain hardening occurs, the solution becomes unstable. We set the value of the hardening modulus $H=-\left(\partial f / \partial \boldsymbol{\varepsilon}^{p}\right)^{T}(\partial f / \partial \boldsymbol{\sigma})$ to be $8 \times 10^{2} \mathrm{MPa}$. We can understand the meaning of this parameter by considering a uniaxial problem and a simple yielding function $f=\sigma$ where $\sigma$ is uniaxial stress. Using Eq. (8), we obtain an increment of uniaxial plastic strain $\varepsilon^{p}$ as $d \varepsilon^{p}=$ $(\partial f / \partial \sigma) d \sigma(\partial f / \partial \sigma) / H$. Using a yielding function $f=\sigma$, we obtain $d \sigma / d \varepsilon^{p}=H$. When $H$ is positive, plastic hardening occurs; however, when $H$ is negative, plastic softening occurs. We set the values of Young's modulus $E$, Poisson's ratio $v$, and the cohesion $c$ to be $8 \times 10^{2} \mathrm{GPa}$,

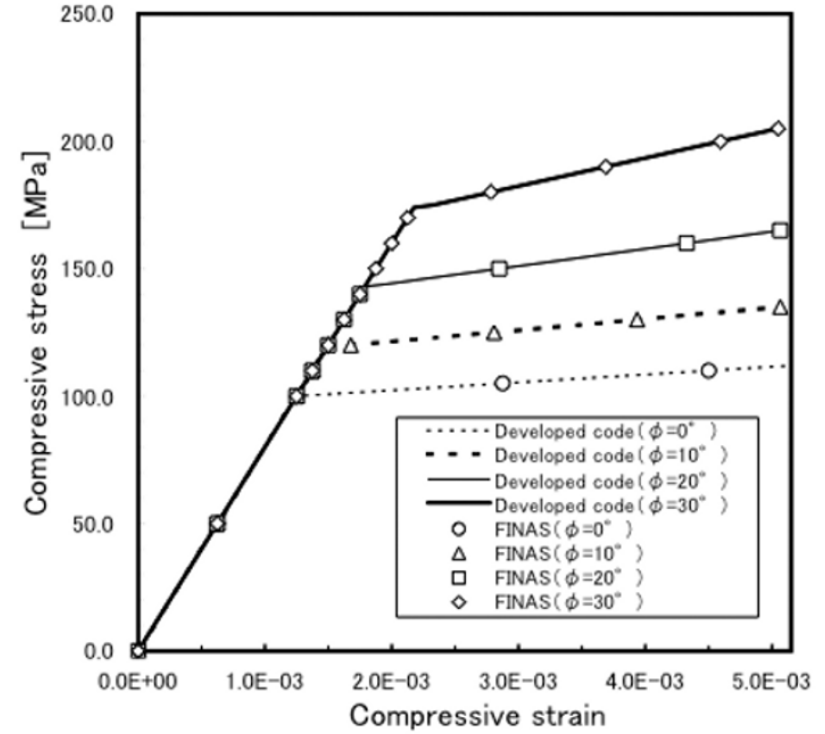

Fig. D.1. Comparison of solutions obtained using our code with those obtained using FINAS for a deformation problem in an elasto-plastic material. We increase the uniform negative vertical load with time at the top of the four-element model in Fig. B.1, which consists of an elasto-plastic material. We change $\phi$ from $0^{\circ}, 10^{\circ}$, and $20^{\circ}$ to $30^{\circ}$. The lines show the changes in the compressive stress with increasing compressive strain for different internal friction angles, which were obtained using our code. The symbols show the changes in the compressive stress with increasing compressive strain, which were obtained using FINAS.

0.25 , and $50 \mathrm{MPa}$, respectively. We change the angle of internal friction $\phi$ from $0^{\circ}, 10^{\circ}$, and $20^{\circ}$, to $30^{\circ}$. Figure D. 1 shows the relationship between the compressive strain and compressive stress, which are calculated by using our code and FINAS. The difference between our solutions and those obtained by using FINAS is less than $0.1 \%$. The results obtained by using our code are almost identical to those obtained by using FINAS.

\section{References}

Bathe, K. J., Finite Element Procedures, Prentice-Hall International, Inc., 1996.

Ellis, S. and B. Stöckhert, Elevated stresses and creep rates beneath the brittle-ductile transition caused by seismic faulting in the upper crust, $J$. Geophys. Res., 109, B05407, doi:10.1029/2003JB002744, 2004.

Ellis, S., S. Wissing, and A. Pfiffner, Strain localization as a key to reconcliling experimentally derived flow-law data with dynamic models of continental collision, Int. J Earth Sci., 90, 168-180, 2001.

Furukawa, Y., Temperature structure in the crust of the Japan arc and the thermal effect of subduction, in Terrestrial Heat Flow and Geothermal Energy in Asia, edited by M. L. Gupta and M. Yamano, pp. 203-219, Oxford and IBH Publishers, New Dehli, 1995.

Garatani, K., H. Nakamura, H. Okuda, and G. Yagawa, High Performance Parallel FEM for Solid Earth, J. Future Generation Computer Systems, 81, 107-114, 2001a.

Garatani, K., Nakajima, H. Okuda, and G. Yagawa, Three-dimensional elasto-static analysis of 100 million degrees of freedom, J. Adv. Eng. Software, 32, 511-518, $2001 \mathrm{~b}$.

Garatani, K., B. Shibazaki, H. Tanaka, Y. Iio, and H. Okuda, Inelastic crustal deformation model by FEM: coexistence of non-linear flow and plastic deformation, Programme and Abstracts, the Seismological Society of Japan, 2003, Fall Meeting, B004, 2003.

Hasegawa, A., J. Nakajima, N. Umino, and S. Miura, Deep structure of the northeastern Japan arc and its implications for crustal deformation and shallow seismic activity, Tectonophysics, 403, 59-75, 2005.

Holbrook, W. S., W. D. Mooney, and N. I. Christensen, The seismic velocity structure of the deep continental crust, in Continental Lower Crust, 
edited by D. M. Fountain, R. Arculus, and R. W. Kay, Elsevier, 1-43, Amsterdam, 1992.

Huismans, R. S., S. J. H. Buiter, and C. Beaumont, Effect of plastic-viscous layering and strain softening on mode selection during lithospheric extension, J. Geophys. Res., 110, B02406, doi:10.1029/2004JB003114, 2005.

Hyodo, M. and K. Hirahara, A viscoelastic model of interseismic strain concentration in Niigata-Kobe Tectonic Zone of central Japan, Earth Planets Space, 55, 667-675, 2003.

Iio, Y., Frictional coefficient on faults in a seismogenic region inferred from earthquake mechanism solutions, J. Geophys. Res., 102, 54035412, 10.1029/96JB03593, 1997.

Iio, Y. and Y. Kobayashi, A physical understanding of large intraplate earthquakes, Earth Planets Space, 54, 1001-1004, 2002.

Iio, Y., T. Sagiya, Y. Kobayashi, and I. Shiozaki, Water-weakened lower crust and its role in the concentrated deformation in the Japanese islands, Earth Planet. Sci. Lett., 203, 245-253, 2002.

Iio, Y., T. Sagiya, N. Umino, T. Nishimura, K. Takahashi, and T. Homma, A comprehensive model of the deformation process in the NagamachiRifu Fault Zone, Earth Planets Space, 56, 1339-1345, 2004.

Iwasaki, T., W. Kato, T. Moriya, A. Hasemi, N. Umino, T. Okada, K. Miyashita, T. Mizogami, T. Takeda, S. Sekine, T. Matsushima, K. Tashiro, and H. Miyamachi, Extensional structure in northern Honshu Arc as inferred from seismic refraction/wide-angle reflection profiling, Geophys. Res. Lett., 28, 2329-2332, 2001.

Iwata, K., T. Kano, H. Atsumo, and H. Takeda, General purpose nonlinear analysis problem FINAS for elevated temperature design of FBR Components, J. Pressure Vessel Piping, 66, 119-137, 1982.

Johnston, A. C. and L. R. Kanter, Earthquakes in stable continental crust, Sci. Am., 262(3), 68-75, 1990.

Kenner, S. and P. Segall, A mechanical model for intraplate earthquakes: Application to the New Madrid, Science, 289, 2329-2332, 2000.

Kohlstedt, D. L., B. Evans, and S. J. Mackwell, Strength of the lithosphere: Constraints imposed by laboratory experiments, J. Geophys. Res., 100, 17587-17602, 10.1029/95JB01460, 1995.

Lavier, L. L. and W. R. Buck, Half graben versus large-offset low-angle normal fault: Importance of keeping cool during normal faulting, $J$. Geophys. Res., 107, 2122, doi:10.1029/2001JB000513, 2002.

Matsu'ura, M. and T. Sato, Loading mechanism and scaling relations of large interpolate earthquakes, Tectonophysics, 277, 189-198, 1997.

Melosh, H. J. and A. Raefsky, The dynamical origin of subduction zone topography, Geophys. J. R.A.S., 60, 333-354, 1980.

Miura, S., T. Sato, A. Hasegawa, Y. Suwa, K. Tachibana, and S. Yui, Strain concentration zone along the volcanic front derived by GPS observa- tions in NE Japan arc, Earth Planets Space, 56, 1347-1355, 2004.

Nakajima, J., T. Matsuzawa, A. Hasegawa, and D. Zhao, Threedimensional structure of $\mathrm{Vp}, \mathrm{Vs}$ and $\mathrm{Vp} / \mathrm{Vs}$ beneath northeastern Japan: Implications for arc magmatism and fluids, J. Geophys. Res., 106, 21843-21857, 2001.

Nishimoto, S., M. Ishikawa, M. Arima, and T. Yoshida, Laboratory measurement of P-wave velocity in crustal and upper mantle xenoliths from Ichino-megata, NE Japan: ultrabasic hydrous lower crust beneath the NE Honshu arc, Tectonophysics, 396, 245-259, 2005.

Owen, D. R. J. and E. Hinton, Finite Elements in Plasticity: Theory and Practice, Pineridge Press Limited, 1980.

Ranalli, G., Rheology of the Earth, second edition, Chapman \& Hall, 1995. Regenauer-Lieb, K., D. A. Yuen, and J. Branlund, The initiation of Subduction: Criticality by addition of water, Science, 294, 578-580, 2001.

Sagiya, T., S. Miyazaki, and T. Tada, Continupus GPS arrays and presentday crustal deformation of Japan, Pure Appl. Geophys., 157, 23032322, 2000.

Sato, H., N. Hirata, T. Iwasaki, M. Matsubara, and T. Ikawa, Deep seismic reflection profiling across the Ou Backbone range, northern Honshu Island, Japan, Tectonophysics, 355, 41-52, 2002.

Shimamoto, T., Rheology of rocks and plate tectonics, in Comprehensive Rock Engineering: Principles, Practice \& Projects (volume 1), edited by J. A. Hudson, pp. 93-109, Pergamon Press, Oxford, 1993.

Tanaka, A. and Y. Ishikawa, Temperature distribution and focal depth in the crust of the northeastern Japan, Earth Planets Space, 54, 1109-1113, 2002.

Tse, S. T. and J. R. Rice, Crustal earthquake instability in relation to the depth variation of frictional slip properties, J. Geophys. Res., 91, 9452 9472, 1986.

Tullis, T. E., F. G. Horowitz, and J. Tullis, Flow laws of polyphase aggregates from end-member flow laws, J. Geophys. Res., 96, 8081-8096, 1991.

Umino, N., H. Ujikawa, S. Hori, and A. Hasegawa, Distinct S-wave reflectors (bright spots) detected beneath the Nagamachi-Rifu fault, NE Japan, Earth Planets Space, 54, 1021-1026, 2002.

Yamasaki, T. and T. Seno, High strain rate zone in central Honshu resulting from the viscosity heterogeneities in the crust and mantle, Earth Planet. Sci. Lett., 232, 13-27, 2005.

Zienkiewicz, O. C. and R. L. Taylor, The Finite Element Method, McGrawHill, 4th edition, volumes 1 and 2, 1994.

B. Shibazaki (e-mail: bshiba@kenken.go.jp), K. Garatani, and H. Okuda 